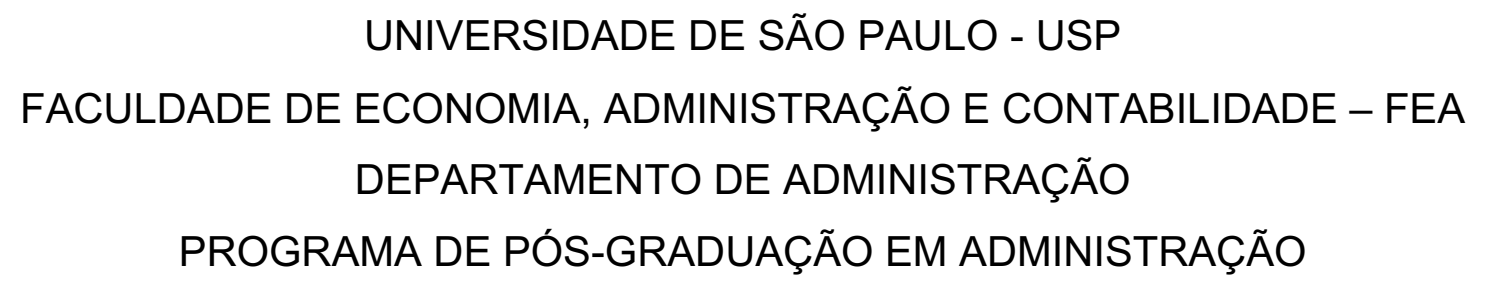

ANÁLISE DAS VARIÁVEIS MACROECONÔMICAS E FINANCEIRAS QUE AFETAM A FORMAÇÃO DE PREÇO DOS TÍTULOS DE DÍVIDA EXTERNA DOS PAÍSES DA ZONA EURO

Sabrina Jaime Loureiro

Orientador: Prof. Dr. José Roberto Securato

Co-orientadora: Profa. Dra. Natalia Poiatti

SÃO PAULO

2018 
Prof. Dr. Marco Antonio Zago

Reitor da Universidade de São Paulo

Prof. Dr. Adalberto Américo Fischmann

Diretor da Faculdade de Economia, Administração e Contabilidade

Prof. Dr. Roberto Sbragia

Chefe do Departamento de Administração

Prof. Dr. Moacir de Miranda Oliveira Júnior

Coordenador do Programa de Pós-Graduação em Administração 
SABRINA JAIME LOUREIRO

\title{
ANÁLISE DAS VARIÁVEIS MACROECONÔMICAS E FINANCEIRAS QUE AFETAM A FORMAÇÃO DE PREÇO DOS TÍTULOS DE DÍVIDA EXTERNA DOS PAÍSES DA ZONA EURO
}

\begin{abstract}
Dissertação apresentada ao Programa de Pós-Graduação em Administração de Departamento de Administração da Faculdade de Economia, Administração e Contabilidade da Universidade de São Paulo, como requisito parcial para a obtenção do título de Mestre em Ciências.
\end{abstract}

Orientador: Prof. Dr. José Roberto Securato Co-orientadora: Profa. Dra. Natalia Poiatti

Versão corrigida

SÃO PAULO 
FICHA CATALOGRÁFICA

Elaborada pela Seção de Processamento Técnico do SBD/FEA/USP

Loureiro, Sabrina Jaime

Análise das varáveis macroeconómicas e financeiras que afetam a formaçäo de preço dos títulos de divida externa dos paises da zona euro $t$ Sabrina Jaime Loureiro. -- Säo Paulo, 2017.

$79 \mathrm{p}$.

Dissertaçäo(Mestrado) - Universidade de Säo Paulo, 2017.

Orientador: Jose Roberto Securato.

Co-orientador: Natalia Poiatt.

1. União Europeia 2. Macroeconomia 3. Taxa de juros 4. Risco de crédito 5. Mudança estrutural I. Universidade de Săo Paulo. Faculdade de Economia, Administraçäo e Contabilidade. II. Título.

CDD - 341.242 
Aos meus filhos. 



\section{AGRADECIMENTOS}

Ao Prof. Dr. José Roberto Securato, pela orientação desde o início desta pesquisa, por contribuir para o meu crescimento profissional e, principalmente, por ser professor exemplar em sua dedicação e competência, que me inspiram a alçar novos desafios no mundo das finanças.

À Profa. Dra. Natalia Poiatti, pela orientação, pelo apoio, pela amizade e, especialmente, pela atenção nas revisões e sugestões, fundamentais para o êxito desta pesquisa.

Ao Prof. Dr. José Roberto Savoia, por seu apoio e amizade, por acreditar no meu trabalho e por me incentivar a navegar pelo mundo acadêmico.

A todos os professores da Pós-graduação da FEA-USP que de alguma forma contribuíram para minha formação.

Ao Prof. Dr. Luiz Paulo Fávero e ao Prof. Dr. Ricardo Humberto Rocha, por suas sugestões valiosas que tanto contribuíram para o resultado do trabalho.

Aos meus amigos e familiares, que sempre me incentivaram a perseguir meus sonhos e me apoiaram em mais esta jornada. 

"I'm convinced that, in the long term, a monetary union includes a joint debt policy under strict, mutually agreed upon conditions"

"Europe will either succeed or fail together"

Jean-Claude Juncker, 2012 



\section{RESUMO}

LOUREIRO, Sabrina Jaime. Análise das variáveis macroeconômicas e financeiras que afetam a formação de preço dos títulos de dívida externa dos países da zona Euro. 2018. 81 f. Dissertação (Mestrado em Administração) - Faculdade de Economia, Administração e Contabilidade, Universidade de São Paulo, São Paulo, 2018.

Este trabalho analisa a importância das variáveis macroeconômicas fundamentais na explicação do diferencial de juros dos países periféricos europeus depois de 2009. Mostramos que, após a Alemanha rejeitar o resgate dos títulos gregos, os investidores não só passaram a exigir maiores rentabilidades dos países periféricos com maior endividamento em relação ao PIB como também passaram a utilizar outras medidas macroeconômicas fundamentais para atribuir preço aos títulos soberanos: o crescimento real do PIB e a taxa efetiva de câmbio. Também verificamos que mudanças na volatilidade do S\&P medidas pelo índice Vix passaram a ser significativas na formação de preço dos títulos após 2010, demonstrando que os investidores consideraram os países periféricos europeus menos seguros após essa decisão de a Alemanha não resgatar os títulos gregos.

Palavras-chave: União Europeia, macroeconomia, taxa de juros, risco de crédito, mudança estrutural. 



\begin{abstract}
LOUREIRO, Sabrina Jaime. Analysis of the macroeconomic and financial variables that influence the price of Eurozone countries' external debt. 2018. $81 \mathrm{f}$. Dissertação (Mestrado em Administração) - Faculdade de Economia, Administração e Contabilidade, Universidade de São Paulo, São Paulo, 2018.

This work investigates the importance of macroeconomic fundamentals in explaining the increase in the peripheral European sovereign spreads after 2009. After Germany refused to bail-out Greece, we show that investors not only increased the peripheral European sovereign spreads explained by the debt to GDP ratio, but also started pricing risk by observing additional macroeconomic fundamentals: the real gdp growth rate and the real effective exchange rate. We also show that changes in the Vix are priced only after 2010, demonstrating that investors considered European peripheral countries less safe after Germany decided not to bail-out Greece.
\end{abstract}

Keywords: European Union, macroeconomic variables, interest rates, credit risk, structural change. 


\section{SUMÁRIO}

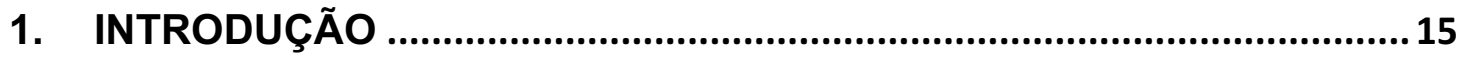

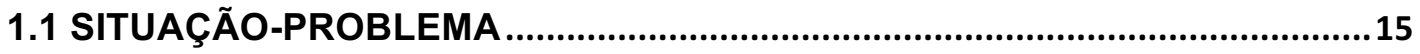

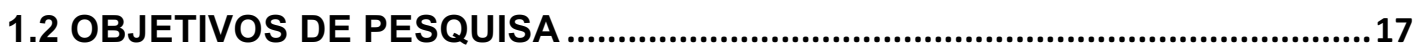

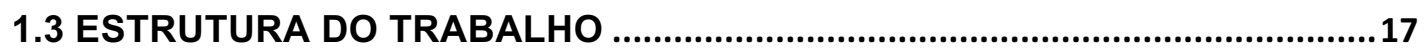

2. FUNDAMENTAÇÃO TEÓRICA .......................................................... 19

2.1 EQUILÍBRIO FISCAL NA UNIÃO EUROPEIA .......................................19

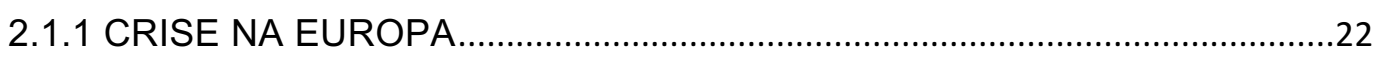

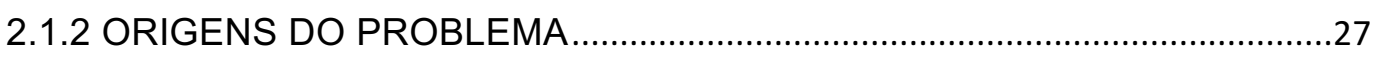

2.1.3 SOCORRO FINANCEIRO E PERSPECTIVAS DE LONGO PRAZO ..........31

2.2 O PREÇO DO RISCO DE CRÉDITO SOBERANO ........................................32

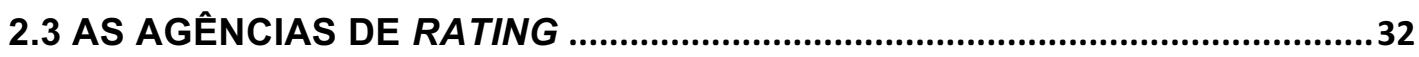

2.4 VARIÁVEIS ECONÔMICAS E O RISCO DE CRÉDITO DOS PAÍSES..............35

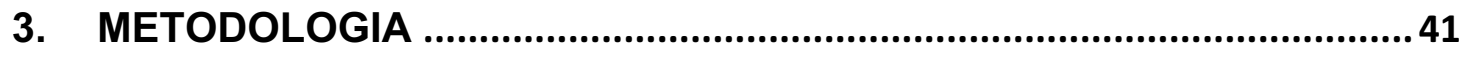

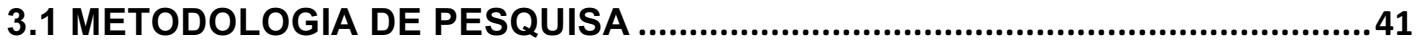

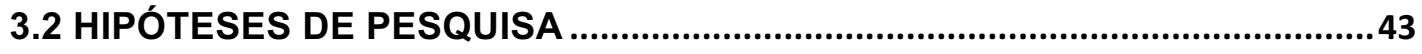

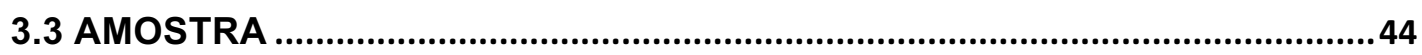

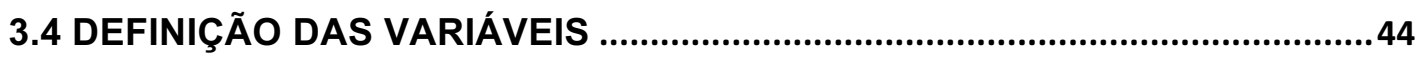

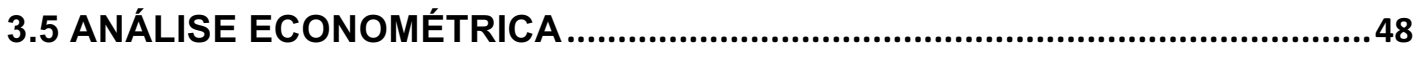

4. ANÁLISE DOS RESULTADOS ................................................................ 53

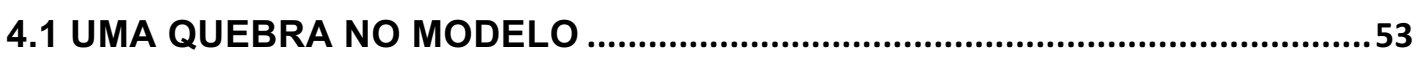

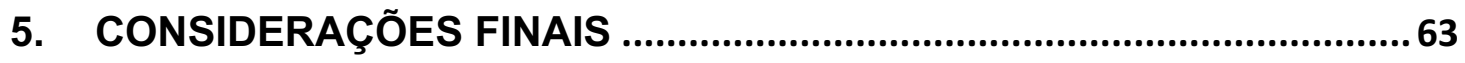

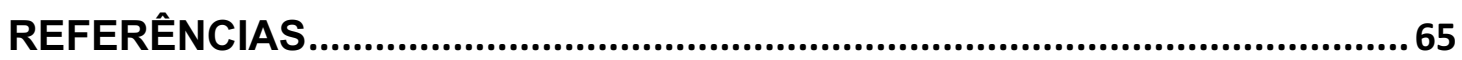

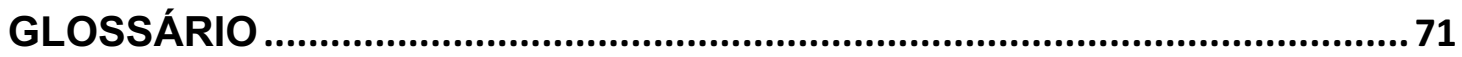

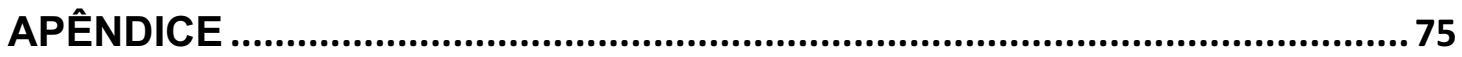






\section{INTRODUÇÃO}

\subsection{SITUAÇÃO-PROBLEMA}

A União Europeia é hoje um dos principais blocos políticos do mundo. Tem uma área aproximada de 4 milhões de quilômetros quadrados e cerca de 500 milhões de habitantes. Concentra a terceira maior população do planeta, atrás apenas da China e da Índia, e 22\% do PIB nominal, o produto interno bruto nominal, global em 2016.

Entre os 28 países da União Europeia, 18 deles têm uma moeda comum, o Euro, e são este grupo de países que denominamos "zona Euro": Alemanha, Áustria, Bélgica, Chipre, Eslováquia, Eslovênia, Espanha, Estônia, Finlândia, França, Grécia, Irlanda, Itália, Letônia, Lituânia, Luxemburgo, Malta, Holanda e Portugal.

A força econômica do bloco europeu era comparável aos Estados Unidos quando a moeda única foi implementada.

Entretanto, há uma grande disparidade entre os países da zona Euro. Alemanha, França, Holanda, Bélgica, Finlândia, Luxemburgo e Áustria são os países mais ricos da zona, denominados "países centrais". A maioria deles tem uma grande força industrial, e suas economias são dominantes no bloco europeu. Além desses, formam o bloco, ainda, países que são provenientes da antiga Europa do Leste, com economias mais fracas e uma indústria ainda bastante incipiente. Somam-se ao grupo: Chipre, Espanha, Grécia, Irlanda, Itália, Malta e Portugal, os chamados "países periféricos".

No período pré-crise americana, em 2008, a União Europeia apresentava taxas de crescimento elevadas, e havia a crença na convergência econômica dos países da zona Euro, os quais eram vistos pelo mercado financeiro como um só risco.

Os investidores entendiam o risco da União Europeia como se todos os países do bloco representassem um único risco comum, como se a União Europeia fosse os Estados Unidos da Europa. 
Os países periféricos europeus importavam a credibilidade dos países centrais, e, beneficiados pela alta liquidez global, captaram volumes de dívidas de baixo custo. O endividamento de alguns países da zona Euro foi muito além de suas possibilidades financeiras e levou a um nível de endividamento insustentável.

Os países ditos periféricos são assim especificados por se referirem ao grupo de países da zona Euro com economias mais frágeis. Essa denominação surgiu com a imprensa internacional, logo no início da crise europeia. Esse grupo inclui os países provenientes da antiga URSS e os países do sul da Europa denominados PIIGS: Portugal, Irlanda, Itália, Grécia e Espanha. O termo PIIGS foi cunhado pela imprensa inglesa no início da década de 1990 e não integrava a Irlanda; inicialmente, o termo era usado para se referir aos países do sul da Europa.

Quando a economia europeia começou a arrefecer, junto com a economia mundial, as idiossincrasias dos países-membros ficaram evidentes, e a comunidade internacional voltou sua atenção para o problema do insustentável endividamento dos países periféricos, o que resultou num movimento de correção nos preços.

A partir de então, o risco de crédito soberano europeu - medido pelo prêmio de risco dos bônus soberanos, ou seja, o diferencial da taxa de retorno entre os títulos soberanos de mesma maturidade - sofreu um ajuste em razão da diferenciação de risco. Esse tem sido um tema extremamente relevante no meio financeiro, despertando estudos nos mais relevantes centros de pesquisa em finanças do mundo.

O presente estudo examina as principais variáveis macroeconômicas e financeiras indicadas na literatura, relacionadas com a formação de preço do risco de crédito soberano para os países europeus da zona Euro. A maior contribuição do trabalho é reexaminar o tema, anos depois da crise europeia, trazendo um novo olhar para a dinâmica de preços dos títulos europeus.

As questões de pesquisa que pretendemos responder são: as variáveis macroeconômicas de cada país estão relacionadas com a formação de preço do risco de crédito soberano dos países europeus? E, ainda: houve uma ruptura no modelo de formação de preço dos títulos soberanos europeus no período pré e pós-crise? 
Para a análise, trabalhamos com dados dos 12 países europeus que formavam o bloco em janeiro de 2001, tomando-se a Alemanha como país-âncora. O período analisado é de janeiro de 2001 a junho de 2014. O marco inicial, em 2001, deve-se ao ano de inclusão da Grécia à União Europeia, e finalizamos em 2014 pela indisponibilidade de dados mais recentes.

\subsection{OBJETIVOS DE PESQUISA}

São objetivos desta pesquisa:

(a) Analisar a influência do perfil de endividamento e das variáveis macroeconômicas na formação de preço do risco de crédito soberano para os países da zona Euro.

(b) Verificar a relação das variáveis financeiras globais, relacionadas ao nível de aversão ao risco do investidor internacional, com os preços dos títulos de dívida pública dos países da zona Euro no mercado secundário.

(c) Avaliar se houve uma ruptura no modelo de precificação do prêmio de risco de crédito soberano durante o período analisado.

\subsection{ESTRUTURA DO TRABALHO}

Este trabalho está estruturado em cinco capítulos. Na Introdução, estão definidos os objetivos da pesquisa, os aspectos metodológicos e as contribuições.

No capítulo dois, Fundamentação teórica, apresentamos um breve relato do problema da dívida pública europeia, procurando identificar suas origens e as estratégias utilizadas para amenizar tal problema. Também analisamos a literatura acadêmica recente sobre a formação de preço do risco soberano, dando ênfase às principais pesquisas da área.

No capítulo três, Metodologia, determinamos as hipóteses de pesquisa e apresentamos o ferramental estatístico utilizado na análise. Ainda, nesse capítulo, 
descrevemos as variáveis incluídas no estudo e as justificamos à luz da literatura acadêmica existente sobre o tema.

No capítulo quatro, são feitas a análise dos resultados e a discussão das hipóteses de pesquisa.

O capítulo cinco, Considerações finais, conclui o trabalho numa síntese da pesquisa, apresentando sugestões para futuros estudos. 


\section{FUNDAMENTAÇÃO TEÓRICA}

\subsection{EQUILÍBRIO FISCAL NA UNIÃO EUROPEIA}

O Tratado de Maastricht foi assinado em 7 de fevereiro de 1992 e deu origem ao que hoje é a União Europeia, representando um marco na união da Europa, determinando sua integração econômica e a consequente unificação política.

Em 1 de Janeiro de 1999, foi introduzido o Euro, que se tornou a moeda oficial de 11 Estados-Membros, substituindo as antigas moedas nacionais. O Euro foi inicialmente utilizado como moeda virtual nas operações de pagamento que não envolviam notas e moedas e para fins contábeis; posteriormente, em 1 de janeiro de 2002, o Euro foi introduzido sob a forma de notas e moedas.

A União Econômica e Monetária (UEM), iniciada com a criação do Euro, pressupõe a existência de uma política monetária única para todos e de políticas fiscais descentralizadas, de responsabilidade dos Estados-Membros participantes.

A eliminação das moedas nacionais fez com que os países perdessem a opção de desvalorizar suas moedas em caso de choques adversos, econômicos e financeiros, e, em decorrência, a política fiscal passou a ganhar ainda mais importância como ferramenta de política macroeconômica anticíclica (Lane, 2012, p. 49).

Para evitar pressões sobre a inflação dos preços e as taxas de juros, que teriam repercussões negativas sobre todos os Estados-Membros, houve, então, a necessidade de definir-se um conjunto de regras para organizar a política orçamentária dos Estados-Membros, a fim de garantir a disciplina fiscal.

Nesse contexto, o Tratado de Maastricht, ou, formalmente, o Tratado da União Europeia, incluiu, no seu texto, um conjunto de artigos com o objetivo de supervisionar a situação fiscal dos Estados-Membros da União Europeia (UE). Entre os principais artigos que tratam da questão orçamentária, destacam-se: 
- Artigo 1010: Estabelece a proibição de linhas de crédito ou a aquisição em mercado primário de dívida pública pelo Banco Central Europeu (BCE) ou pelos bancos centrais nacionais.

- Artigo 103: Isenta a UE e os Estados-Membros de serem responsabilizados ou de assumirem compromissos das administrações públicas de um dado EstadoMembro, o que é conhecido pelo mercado como "regra de não bail-out".

- Artigo 104: Define o que deve ser considerado um déficit excessivo e descreve os passos associados à correção do déficit, bem como as medidas a serem tomadas no caso de não cumprimento.

O Banco Central Europeu define o déficit como as necessidades líquidas de financiamento das administrações públicas, tal como decorrem do Sistema Europeu de Contas, e a dívida como o valor nominal da dívida bruta consolidada das administrações públicas.

O Tratado de Maastricht estabeleceu critérios de convergência para os Estados-Membros, os quais são empregados, até hoje, para a admissão de novos membros ao grupo. Os principais critérios são:

- Déficit público: o déficit público não deverá ultrapassar 3\% do PIB.

- Endividamento: estabelece o limite de $60 \%$ do PIB para a dívida pública, isto é, em cada ano, o quociente entre o valor da dívida pública nominal e o PIB não deverá ultrapassar $60 \%$.

- Taxa de câmbio: as margens de flutuação normais previstas no mecanismo de taxas de câmbio devem ser respeitadas, sem tensões graves, durante, pelo menos, os últimos dois anos anteriores à análise.

- Inflação: a taxa de inflação não deve superar em mais que 1.5\% a média das taxas de inflação dos três Estados-Membros com menor índice de inflação (excluídos os casos de deflação) durante o ano precedente ao exame para admissão. 
- Taxa de juros: a taxa de juros nominal de longo prazo não deve superar em mais que $2 \%$ a média das taxas de inflação dos três Estados-Membros com menor índice de inflação durante o ano precedente ao exame para admissão.

Esses critérios de convergência têm por objetivo assegurar que o desenvolvimento econômico da União Econômica e Monetária seja equilibrado. $O$ cumprimento de tais critérios constitui a condição prévia à adesão ao Euro.

Uma vez na zona Euro, os Estados-Membros devem continuar a respeitar os critérios relativos ao déficit orçamental e à dívida pública. O Pacto de Estabilidade e Crescimento, aprovado em 1997, tem o objetivo preventivo de regular a situação orçamentária dos Estados-Membros, e, por meio dele, estes firmaram o compromisso de respeitar, no médio prazo, um saldo orçamental de equilíbrio.

O Pacto de Estabilidade será traduzido em dois Regulamentos: vigilância multilateral e procedimento no caso de déficits excessivos.

O objetivo orçamental de médio prazo determinado no Pacto de Estabilidade e Crescimento preserva a margem de segurança em relação ao limite para o déficit orçamental máximo de 3 por cento do PIB. Os países que não se enquadram nesse limite têm o prazo-limite para a correção de situações de déficit excessivo de um ano após a sua identificação. O prazo de correção pode ser relativizado na existência de circunstâncias especiais, de pronunciada crise econômica, justificando o prolongamento desse prazo por mais um ano. Caso não haja correção, são aplicadas sanções que podem, no limite, culminar na expulsão do país da zona Euro.

Em 1998, onze países europeus satisfaziam aos critérios e seriam os membros fundadores da União Econômica Monetária: Áustria, Bélgica, França, Finlândia, Portugal, Holanda, Alemanha, Itália, Irlanda, Luxemburgo e Espanha. A Grécia se juntaria ao grupo em 2001 e, posteriormente, Chipre, Malta, Estônia, Eslováquia e Eslovênia. 


\subsubsection{CRISE NA EUROPA}

Até 2007, os países da União Europeia experimentaram uma fase de elevado crescimento econômico, propiciado pela conjuntura internacional de farta liquidez global e confiança nos mercados financeiros.

Nesse período pré-crise, os países periféricos, como Portugal, Espanha, Itália, Irlanda e Grécia, importavam a credibilidade dos países centrais. Havia a crença na convergência econômica dos países da zona Euro, e os investidores não distinguiam o risco de crédito entre os países periféricos e os países centrais.

Os prêmios de risco dos títulos de 10 anos dos países europeus da zona Euro ficaram, por muito tempo, artificialmente baixos, e os países periféricos captaram grandes volumes de dívida. $O$ índice de endividamento crescente foi parcialmente mascarado pelo período de crescimento econômico que o mundo estava atravessando. Esses dados podem ser visualizados na Figura 1 e na Tabela 1, a seguir.

Figura 1 - Evolução do estoque de dívida em proporção ao PIB dos Estados-Membros da UE

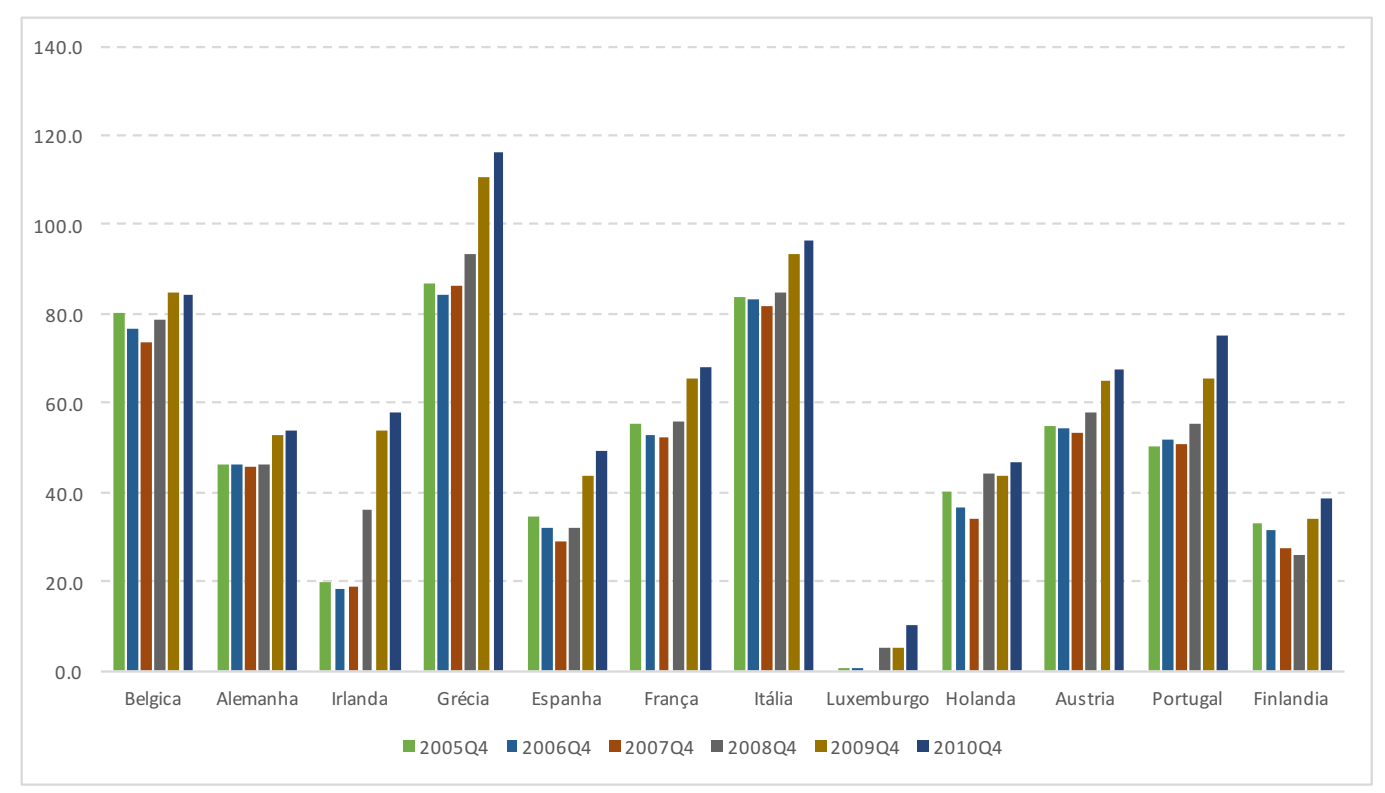

Fonte: Elaborado pela autora. Dados do Eurostat. 
Tabela 1 - Evolução do prêmio de risco do Título de 10 anos com relação à Alemanha

\begin{tabular}{|cccccccccccc|} 
& Belgica & Irlanda & Grécia & Espanha & França & Itália & Luxemburgo & Holanda & Austria & Portugal \\
\hline $\mathbf{2 0 0 0}$ & 0.38 & 0.25 & 0.71 & 0.30 & 0.15 & 0.39 & 0.35 & 0.14 & 0.31 & 0.38 \\
$\mathbf{2 0 0 1}$ & 0.27 & 0.18 & 0.43 & 0.28 & 0.12 & 0.34 & -0.19 & 0.16 & 0.24 & 0.29 \\
\hline $\mathbf{2 0 0 2}$ & 0.17 & 0.19 & 0.29 & 0.13 & 0.07 & 0.26 & -0.36 & 0.08 & 0.14 & 0.18 \\
\hline $\mathbf{2 0 0 3}$ & 0.08 & 0.04 & 0.16 & 0.05 & 0.05 & 0.16 & -1.00 & 0.05 & 0.09 & 0.12 \\
\hline $\mathbf{2 0 0 4}$ & 0.08 & 0.03 & 0.20 & 0.07 & 0.08 & 0.22 & -1.14 & 0.06 & 0.07 & 0.08 \\
\hline $\mathbf{2 0 0 5}$ & 0.05 & -0.02 & 0.22 & 0.04 & 0.05 & 0.21 & -0.74 & 0.03 & 0.03 & 0.14 \\
\hline $\mathbf{2 0 0 6}$ & 0.04 & -0.01 & 0.27 & 0.03 & 0.03 & 0.27 & -0.04 & 0.04 & 0.04 & 0.18 \\
\hline $\mathbf{2 0 0 7}$ & 0.18 & 0.19 & 0.32 & 0.13 & 0.14 & 0.34 & 0.43 & 0.12 & 0.13 & 0.26 \\
\hline $\mathbf{2 0 0 8}$ & 0.70 & 1.06 & 1.53 & 0.66 & 0.40 & 1.16 & 0.90 & 0.45 & 0.64 & 0.80 \\
\hline $\mathbf{2 0 0 9}$ & 0.45 & 1.63 & 1.78 & 0.60 & 0.34 & 0.87 & 0.65 & 0.31 & 0.43 & 0.66 \\
\hline $\mathbf{2 0 1 0}$ & 0.96 & 5.10 & 8.43 & 2.10 & 0.42 & 1.60 & 0.40 & 0.24 & 0.49 & 3.90 \\
\hline $\mathbf{2 0 1 1}$ & 2.53 & 6.51 & 17.10 & 3.73 & 1.26 & 4.68 & 0.39 & 0.50 & 1.20 & 10.30 \\
\hline $\mathbf{2 0 1 2}$ & 0.91 & 3.31 & 14.79 & 4.19 & 0.74 & 3.41 & 0.15 & 0.29 & 0.51 & 6.55 \\
\hline $\mathbf{2 0 1 3}$ & 0.72 & 1.80 & 6.85 & 2.40 & 0.58 & 2.40 & 0.33 & 0.38 & 0.40 & 4.37 \\
\hline $\mathbf{2 0 1 4}$ & 0.35 & 0.84 & 7.23 & 1.29 & 0.41 & 1.53 & 0.06 & 0.21 & 0.26 & 2.35 \\
\hline $\mathbf{2 0 1 5}$ & 0.33 & 0.59 & 7.28 & 1.18 & 0.36 & 1.09 & -0.25 & 0.20 & 0.31 & 1.96 \\
\hline
\end{tabular}

Fonte: Elaborado pela autora. Dados do Eurostat. Prêmio de risco calculado tomando-se o yield do título de 10 anos do país menos o yield do título de 10 anos da Alemanha.

O problema veio à tona quando a economia europeia começou a se enfraquecer, após o choque da crise americana do subprime (créditos de risco oferecidos a tomadores que não ofereciam garantias), que colapsou o mercado financeiro global na crise americana de crédito hipotecário, em 2008.

Vários bancos europeus detinham grandes posições em ativos tóxicos americanos e, além disso, alguns países periféricos da zona do Euro tiveram que lidar com suas próprias crises imobiliárias.

Alguns Estados-Membros tiveram que intervir no resgate de suas instituições financeiras e o fizeram à custa da ampliação do déficit público. O endividamento cresceu ao mesmo tempo em que o PIB se contraía, o que chamou a atenção para o alto nível de endividamento das economias periféricas.

A Comissão Europeia foi acusada de não ter zelado pelo respeito ao Pacto de Estabilidade e Crescimento (PEC), e o Euro passou a sofrer fortes ataques especulativos como consequência da fragilização fiscal da União Europeia. 
Tabela 2 - Indicativos de desenvolvimento dos países da Zona Euro

\begin{tabular}{|c|c|c|c|c|c|c|c|c|c|}
\hline País & Indicador & & 2000 & & 2005 & & 2010 & & 2015 \\
\hline \multirow[t]{10}{*}{ Alemanha } & PIB (current US\$ Bilhoes) & $\$$ & $1,1,950$ & $\$$ & 2,861 & $\$$ & $3,3,417$ & $\$$ & $3,3,364$ \\
\hline & Crescimento do PIB (anual \%) & & 3.0 & & 0.7 & & 4.1 & & 1.7 \\
\hline & PIB per capita (current US\$) & $\$$ & 23,719 & $\$$ & 34,697 & $\$$ & 41,786 & $\$$ & 41,177 \\
\hline & Crescimento PIB per capita (anual \%) & & 2.8 & & 0.8 & & 4.2 & & 0.8 \\
\hline & Poupança domestica bruta (\% PIB) & & 24.2 & & 23.9 & & 24.8 & & 26.8 \\
\hline & Formaçao de capital fixo (\% PIB) & & 23.0 & & 19.1 & & 19.4 & & 19.9 \\
\hline & Expectativa de vida ao nascer (anos) & & 77.9 & & 78.9 & & 80.0 & & 81.1 \\
\hline & Densidade populacional (pessoas por km quadrado) & & 235.6 & & 236.5 & & 234.6 & & 234.1 \\
\hline & Populaçao total (mil) & & 82,212 & & 82,469 & & 81,777 & & 81,687 \\
\hline & Area total (km quadrados) & & 357,030 & & 357,090 & & 357,127 & & 357,380 \\
\hline \multirow[t]{10}{*}{ Austria } & PIB (current US\$ Bilhoes) & $\$$ & 196 & $\$$ & 315 & $\$$ & 390 & $\$$ & 377 \\
\hline & Crescimento do PIB (anual \%) & & 3.4 & & 2.1 & & 1.9 & & 1.0 \\
\hline & PIB per capita (current US\$) & $\$$ & 24,517 & $\$$ & 38,242 & $\$$ & 46,657 & $\$$ & 43,665 \\
\hline & Crescimento PIB per capita (anual \%) & & 3.1 & & 1.4 & & 1.7 & & -0.1 \\
\hline & Poupança domestica bruta (\% PIB) & & 27.4 & & 27.0 & & 26.0 & & 27.5 \\
\hline & Formaçao de capital fixo (\% PIB) & & 25.7 & & 23.1 & & 21.6 & & 22.6 \\
\hline & Expectativa de vida ao nascer (anos) & & 78.1 & & 79.3 & & 80.6 & & 81.8 \\
\hline & Densidade populacional (pessoas por km quadrado) & & 97.0 & & 99.6 & & 101.3 & & 104.6 \\
\hline & Populaçao total (mil) & & 8,012 & & 8,228 & & 8,363 & & 8,633 \\
\hline & Area total (km quadrados) & & 83,879 & & 83,879 & & 83,879 & & 83,879 \\
\hline \multirow[t]{10}{*}{ Belgica } & PIB (current US\$ Bilhoes) & $\$$ & 238 & $\$$ & 387 & $\$$ & 484 & $\$$ & 455 \\
\hline & Crescimento do PIB (anual \%) & & 3.6 & & 2.1 & & 2.7 & & 1.5 \\
\hline & PIB per capita (current US\$) & $\$$ & 23,207 & $\$$ & 36,967 & $\$$ & 44,380 & $\$$ & 40,357 \\
\hline & Crescimento PIB per capita (anual \%) & & 3.4 & & 1.5 & & 1.8 & & 0.9 \\
\hline & Poupança domestica bruta (\% PIB) & & 26.4 & & 27.3 & & 24.5 & & 24.9 \\
\hline & Formaçao de capital fixo (\% PIB) & & 22.5 & & 22.2 & & 21.8 & & 23.0 \\
\hline & Expectativa de vida ao nascer (anos) & & 77.7 & & 79.0 & & 80.2 & & 81.3 \\
\hline & Densidade populacional (pessoas por km quadrado) & & 338.5 & & 346.1 & & 359.8 & & 372.3 \\
\hline & Populaçao total (mil) & & 10,251 & & 10,479 & & 10,896 & & 11,274 \\
\hline & Area total (km quadrados) & & 30,530 & & 30,530 & & 30,530 & & 30,530 \\
\hline \multirow[t]{10}{*}{ Chipre } & PIB (current US\$ Bilhoes) & $\$$ & 10 & $\$$ & 19 & $\$$ & 26 & $\$$ & 20 \\
\hline & Crescimento do PIB (anual \%) & & 5.7 & & 3.7 & & 1.3 & & 1.7 \\
\hline & PIB per capita (current US\$) & $\$$ & 14,673 & $\$$ & 25,324 & $\$$ & 30,818 & $\$$ & 23,075 \\
\hline & Crescimento PIB per capita (anual \%) & & 4.6 & & 2.2 & & -1.3 & & 2.3 \\
\hline & Poupança domestica bruta (\% PIB) & & 23.2 & & 22.0 & & 16.5 & & 14.8 \\
\hline & Formaçao de capital fixo (\% PIB) & & 20.1 & & 21.5 & & 22.3 & & 13.3 \\
\hline & Expectativa de vida ao nascer (anos) & & 78.0 & & 78.6 & & 79.4 & & 80.3 \\
\hline & Densidade populacional (pessoas por km quadrado) & & 102.1 & & 111.2 & & 120.4 & & 125.6 \\
\hline & Populaçao total (mil) & & 943 & & 1,028 & & 1,113 & & 1,161 \\
\hline & Area total ( $\mathrm{km}$ quadrados) & & 9,250 & & 9,250 & & 9,250 & & 9,250 \\
\hline \multirow[t]{10}{*}{ Eslováquia } & PIB (current US\$ Bilhoes) & $\$$ & 29 & $\$$ & 63 & $\$$ & 90 & $\$$ & 87 \\
\hline & Crescimento do PIB (anual \%) & & 1.2 & & 6.8 & & 5.0 & & 3.8 \\
\hline & PIB per capita (current US\$) & $\$$ & 5,403 & $\$$ & 11,669 & $\$$ & 16,601 & $\$$ & 16,090 \\
\hline & Crescimento PIB per capita (anual \%) & & 1.3 & & 6.7 & & 4.9 & & 3.7 \\
\hline & Poupança domestica bruta (\% PIB) & & 25.0 & & 25.1 & & 22.6 & & 25.6 \\
\hline & Formaçao de capital fixo (\% PIB) & & 27.3 & & 27.3 & & 22.1 & & 23.0 \\
\hline & Expectativa de vida ao nascer (anos) & & 73.1 & & 73.9 & & 75.1 & & 77.2 \\
\hline & Densidade populacional (pessoas por km quadrado) & & 112.0 & & 111.7 & & 112.1 & & 112.8 \\
\hline & Populaçao total (mil) & & 5,389 & & 5,373 & & 5,391 & & 5,424 \\
\hline & Area total (km quadrados) & & 49,030 & & 49,030 & & 49,037 & & 49,035 \\
\hline
\end{tabular}




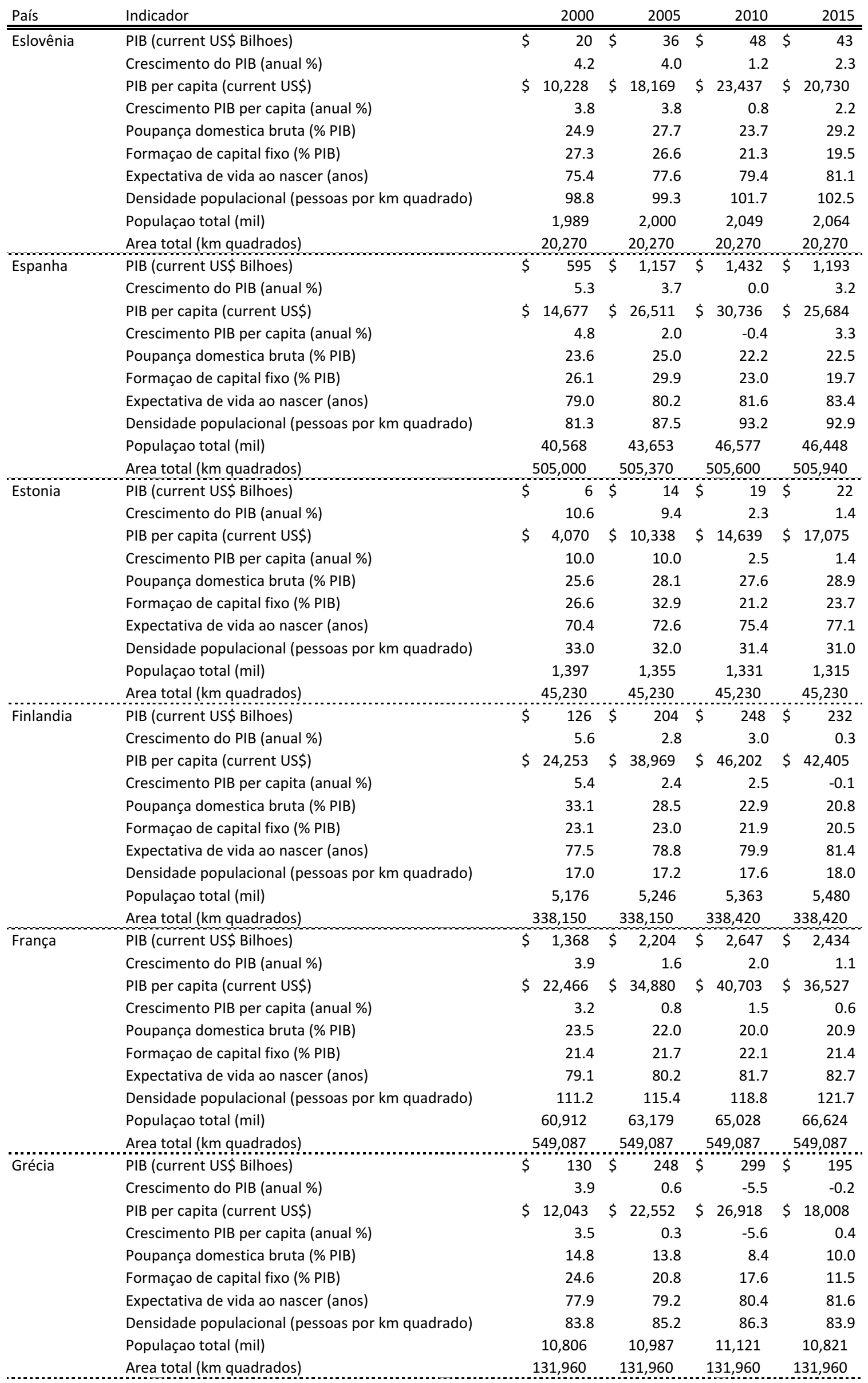




\begin{tabular}{|c|c|c|c|c|c|c|c|}
\hline País & Indicador & & 2000 & & 2005 & 2010 & 2015 \\
\hline \multirow[t]{10}{*}{ Holanda } & PIB (current US\$ Bilhoes) & $\$$ & 413 & $\$$ & 679 & 836 & 750 \\
\hline & Crescimento do PIB (anual \%) & & 4.2 & & 2.2 & 1.4 & 2.0 \\
\hline & PIB per capita (current US\$) & $\$$ & 25,921 & $\$$ & 41,577 & $\$ 50,338$ & $\$ 44,293$ \\
\hline & Crescimento PIB per capita (anual \%) & & 3.5 & & 1.9 & 0.9 & 1.5 \\
\hline & Poupança domestica bruta (\% PIB) & & 29.6 & & 29.6 & 28.8 & 30.1 \\
\hline & Formaçao de capital fixo (\% PIB) & & 22.9 & & 20.6 & 19.7 & 19.4 \\
\hline & Expectativa de vida ao nascer (anos) & & 78.0 & & 79.3 & 80.7 & 81.7 \\
\hline & Densidade populacional (pessoas por km quadrado) & & 471.7 & & 483.4 & 492.6 & 502.8 \\
\hline & Populaçao total (mil) & & 15,926 & & 16,320 & 16,615 & 16,940 \\
\hline & Area total (km quadrados) & & 41,530 & & 41,540 & 41,540 & 41,540 \\
\hline \multirow[t]{10}{*}{ Irlanda } & PIB (current US\$ Bilhoes) & $\$$ & 100 & $\$$ & 212 & $\$ 221$ & $\$ 284$ \\
\hline & Crescimento do PIB (anual \%) & & 9.9 & & 5.8 & 2.0 & 26.3 \\
\hline & PIB per capita (current US\$) & $\$$ & 26,242 & $\$$ & 50,887 & $\$ 48,539$ & $\$ 60,664$ \\
\hline & Crescimento PIB per capita (anual \%) & & 8.5 & & 3.5 & 1.5 & 24.7 \\
\hline & Poupança domestica bruta (\% PIB) & & 38.4 & & 41.2 & 34.0 & 53.4 \\
\hline & Formaçao de capital fixo (\% PIB) & & 23.8 & & 29.8 & 17.6 & 21.2 \\
\hline & Expectativa de vida ao nascer (anos) & & 76.5 & & 78.9 & 80.7 & 81.5 \\
\hline & Densidade populacional (pessoas por km quadrado) & & 55.2 & & 60.4 & 66.2 & 67.9 \\
\hline & Populaçao total (mil) & & 3,805 & & 4,160 & 4,560 & 4,677 \\
\hline & Area total (km quadrados) & & 70,280 & & 70,280 & 70,280 & 70,280 \\
\hline \multirow[t]{10}{*}{ Itália } & PIB (current US\$ Bilhoes) & $\$$ & 1,142 & $\$$ & 1,853 & $\$ 2,125$ & $\$ 1,825$ \\
\hline & Crescimento do PIB (anual \%) & & 3.7 & & 0.9 & 1.7 & 0.8 \\
\hline & PIB per capita (current US\$) & $\$$ & 20,051 & $\$$ & 31,959 & $\$ 35,849$ & $\$ 30,049$ \\
\hline & Crescimento PIB per capita (anual \%) & & 3.7 & & 0.5 & 1.4 & 0.9 \\
\hline & Poupança domestica bruta (\% PIB) & & 21.6 & & 21.0 & 18.6 & 20.2 \\
\hline & Formaçao de capital fixo (\% PIB) & & 20.4 & & 21.2 & 19.9 & 16.8 \\
\hline & Expectativa de vida ao nascer (anos) & & 79.8 & & 80.8 & 82.0 & 83.5 \\
\hline & Densidade populacional (pessoas por km quadrado) & & 193.6 & & 197.1 & 201.5 & 206.5 \\
\hline & Populaçao total (mil) & & 56,942 & & 57,969 & 59,277 & 60,731 \\
\hline & Area total (km quadrados) & & 301,340 & & 301,340 & 301,340 & 301,340 \\
\hline \multirow[t]{10}{*}{ Letônia } & PIB (current US\$ Bilhoes) & $\dddot{\$}$ & 8 & $\$$ & 17 & $\$ \quad 24$ & $\$ \quad 27$ \\
\hline & Crescimento do PIB (anual \%) & & 5.4 & & 10.7 & -3.8 & 2.7 \\
\hline & PIB per capita (current US\$) & $\$$ & 3,353 & $\$$ & 7,559 & $\$ 11,326$ & $\$ 13,667$ \\
\hline & Crescimento PIB per capita (anual \%) & & 6.4 & & 11.9 & -1.8 & 3.6 \\
\hline & Poupança domestica bruta (\% PIB) & & 16.7 & & 20.7 & 17.8 & 21.0 \\
\hline & Formaçao de capital fixo (\% PIB) & & 25.2 & & 31.3 & 19.4 & 21.5 \\
\hline & Expectativa de vida ao nascer (anos) & & 70.3 & & 71.4 & 73.5 & 74.1 \\
\hline & Densidade populacional (pessoas por km quadrado) & & 38.1 & & 36.0 & 33.7 & 31.8 \\
\hline & Populaçao total (mil) & & 2,368 & & 2,239 & 2,098 & 1,978 \\
\hline & Area total (km quadrados) & & 64,559 & & 64,559 & 64,510 & 64,490 \\
\hline \multirow[t]{10}{*}{ Lituânia } & PIB (current US\$ Bilhoes) & $\$$ & 12 & 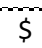 & 26 & $\$ 37$ & $\$ 41$ \\
\hline & Crescimento do PIB (anual \%) & & 3.8 & & 7.7 & 1.6 & 1.8 \\
\hline & PIB per capita (current US\$) & $\$$ & 3,297 & $\$$ & 7,863 & $\$ 11,985$ & $\$ 14,252$ \\
\hline & Crescimento PIB per capita (anual \%) & & 4.6 & & 9.5 & 3.8 & 2.7 \\
\hline & Poupança domestica bruta (\% PIB) & & 12.6 & & 16.8 & 16.1 & 19.2 \\
\hline & Formaçao de capital fixo (\% PIB) & & 19.1 & & 23.4 & 16.9 & 19.3 \\
\hline & Expectativa de vida ao nascer (anos) & & 72.0 & & 71.3 & 73.3 & 75.1 \\
\hline & Densidade populacional (pessoas por km quadrado) & & 55.8 & & 53.0 & 49.4 & 46.4 \\
\hline & Populaçao total (mil) & & 3,500 & & 3,323 & 3,097 & 2,905 \\
\hline & Area total (km quadrados) & & 65,300 & & 65,300 & 65,300 & 65,286 \\
\hline \multirow[t]{10}{*}{ Luxemburgo } & PIB (current US\$ Bilhoes) & $\$$ & 21 & & 37 & $\$ 53$ & $\$ \quad 58$ \\
\hline & Crescimento do PIB (anual \%) & & 8.2 & & 3.2 & 4.9 & 4.0 \\
\hline & PIB per capita (current US\$) & $\$$ & 48,736 & $\$$ & 80,290 & $\$ 104,965$ & $\$ 101,910$ \\
\hline & Crescimento PIB per capita (anual \%) & & 6.8 & & 1.6 & 3.0 & 1.6 \\
\hline & Poupança domestica bruta (\% PIB) & & 47.3 & & 46.6 & 50.8 & 53.6 \\
\hline & Formaçao de capital fixo (\% PIB) & & 20.2 & & 19.1 & 17.6 & 18.2 \\
\hline & Expectativa de vida ao nascer (anos) & & 77.9 & & 79.4 & 80.6 & 82.2 \\
\hline & Densidade populacional (pessoas por km quadrado) & & 168.5 & & 179.6 & 195.7 & 219.9 \\
\hline & Populaçao total (mil) & & 436 & & 465 & 507 & 570 \\
\hline & Area total ( $\mathrm{km}$ quadrados) & & 2,590 & & 2,590 & 2,590 & 2,590 \\
\hline
\end{tabular}




\begin{tabular}{|c|c|c|c|c|c|c|c|c|c|}
\hline País & Indicador & & 2000 & & 2005 & & 2010 & & 2015 \\
\hline \multirow[t]{10}{*}{ Malta } & PIB (current US\$ Bilhoes) & $\$$ & 4 & $\$$ & 6 & $\$$ & 9 & $\$$ & 10 \\
\hline & Crescimento do PIB (anual \%) & & 6.8 & & 3.8 & & 3.5 & & 7.4 \\
\hline & PIB per capita (current US\$) & $\$$ & 11,039 & $\$$ & 15,835 & $\$$ & 21,088 & $\$$ & 23,819 \\
\hline & Crescimento PIB per capita (anual \%) & & 6.1 & & 3.1 & & 3.0 & & 6.3 \\
\hline & Poupança domestica bruta (\% PIB) & & 19.4 & & 18.9 & & 22.7 & & 31.6 \\
\hline & Formaçao de capital fixo (\% PIB) & & 22.5 & & 22.0 & & 21.4 & & 24.7 \\
\hline & Expectativa de vida ao nascer (anos) & & 78.2 & & 79.3 & & 81.4 & & 81.9 \\
\hline & Densidade populacional (pessoas por km quadrado) & & 1219.0 & & 1262.0 & & 1295.3 & & 1349.6 \\
\hline & Populaçao total (mil) & & 390 & & 404 & & 415 & & 432 \\
\hline & Area total (km quadrados) & & 320 & & 320 & & 320 & & 320 \\
\hline \multirow[t]{10}{*}{ Portugal } & PIB (current US\$ Bilhoes) & $\$$ & 118 & $\$$ & 197 & \$ & 238 & $\$$ & 199 \\
\hline & Crescimento do PIB (anual \%) & & 3.8 & & 0.8 & & 1.9 & & 1.6 \\
\hline & PIB per capita (current US\$) & $\$$ & 11,502 & $\$$ & 18,785 & $\$$ & 22,539 & $\$$ & 19,220 \\
\hline & Crescimento PIB per capita (anual \%) & & 3.1 & & 0.6 & & 1.9 & & 2.0 \\
\hline & Poupança domestica bruta (\% PIB) & & 17.7 & & 14.6 & & 13.5 & & 16.2 \\
\hline & Formaçao de capital fixo (\% PIB) & & 28.0 & & 23.1 & & 20.5 & & 15.3 \\
\hline & Expectativa de vida ao nascer (anos) & & 76.3 & & 78.1 & & 79.0 & & 81.5 \\
\hline & Densidade populacional (pessoas por km quadrado) & & 112.5 & & 114.8 & & 115.4 & & 113.1 \\
\hline & Populaçao total (mil) & & 10,290 & & 10,503 & & 10,573 & & 10,358 \\
\hline & Area total (km quadrados) & & 92,120 & & 92,090 & & 92,210 & & 92,225 \\
\hline
\end{tabular}

Fonte: Elaborado pela autora. Dados do Banco Mundial

\subsubsection{ORIGENS DO PROBLEMA}

Na pesquisa de Roszkowski \& Davey (2010), os autores mostram que, a despeito da crença de mercado de que a tolerância ao risco dos investidores diminuiu depois da crise de 2008 , o que mudou realmente foi a maneira como os investidores percebem o risco inerente a seus portfólios.

A avaliação do nível de risco envolve diretamente a percepção do risco, o que significa que existe por parte do investidor uma interpretação da realidade, em que emoções influenciam na maneira como o risco é percebido, de forma que duas pessoas apresentadas à mesma situação percebem o risco de maneira diferente (Kobbeltvedt et al., 2005).

A pesquisa de Mellan (2009) nos mostra que a percepção do investidor sobre o risco muda com frequência e, algumas vezes, de forma irracional, dependendo das condições de mercado. Quando o mercado está em alta, a percepção de risco tende a ser baixa e, em momentos de crise, ela aumenta desproporcionalmente. 
Até 8 de dezembro de 2009, a agência Fitch Ratings categorizava o risco soberano grego como "A-", indicando uma alta qualidade de crédito, 4 notas acima do mínimo para qualificar como "grau de investimento". Em 27 de abril de 2010, a agência Standard \& Poor's (concorrente da Fitch) rebaixou a Grécia, e os títulos gregos passaram a ser considerados bônus especulativos.

O que aconteceu nesse intervalo de menos de 6 meses que levou as principais agências de riscos internacionais a mudarem drasticamente sua percepção de risco sobre os títulos soberanos gregos?

Lamfalussy (1989, p. 97) argumenta em seu trabalho que, a despeito do Tratado de Maastricht ter uma cláusula de não bail-out, a realidade fiscal de cada paísmembro não estaria corretamente precificada na taxa de juros dos títulos de dívida soberanos, sugerindo que os investidores tinham certa expectativa com relação a uma solidariedade entre os Estados-membros e que, numa situação de stress, ver-se-iam pressionados a comprar a dívida do país com problemas para evitar um possível contágio do sistema europeu.

Em 2009, quando a economia europeia começou a se enfraquecer, os yields, (as taxas de juros), dos títulos soberanos descolaram, e o prêmio de risco das economias periféricas cresceu bruscamente, numa nítida correção, quando o mercado percebeu que, apesar de os Estados-Membros formarem uma zona monetária única, detinham características econômicas e creditícias bastante diversas, e não havia tanta certeza de um resgate das economias periféricas pelas economias centrais em caso de default, ou seja, no caso de não pagamento da dívida.

O prêmio de risco que a Grécia tinha de pagar a mais que a Alemanha para captar recursos, no mesmo prazo de 10 anos, passou de 46 pontos-base, no primeiro trimestre de 2008, para 265 pontos-base, no primeiro trimestre de 2009. O ápice se deu no segundo trimestre de 2012, quando o prêmio de risco foi, em média, 2.398 pontos-base maior que a taxa de juros de um título de mesma maturidade da Alemanha (Eurostat, 2016).

Até 2009, os mercados precificavam a Grécia (e outros países europeus) considerando um implícito bail-out. Esperava-se uma convergência da economia 
grega para a economia alemã e, quando se percebeu que essa convergência não havia ocorrido e que não havia a certeza do bail-out, os títulos gregos passaram a ter refletida em seu preço a realidade dos fundamentos da Grécia. A decisão da Alemanha de não recomprar os títulos gregos introduziu um novo risco, não computado anteriormente, e o preço dos bônus gregos aumentou rapidamente entre março e abril de 2010 (Arghyrou \& Tsoukalas, 2011, p.180).

Figura 2 - Evolução do yield do Título de 10 anos dos Estados-Membros da UE

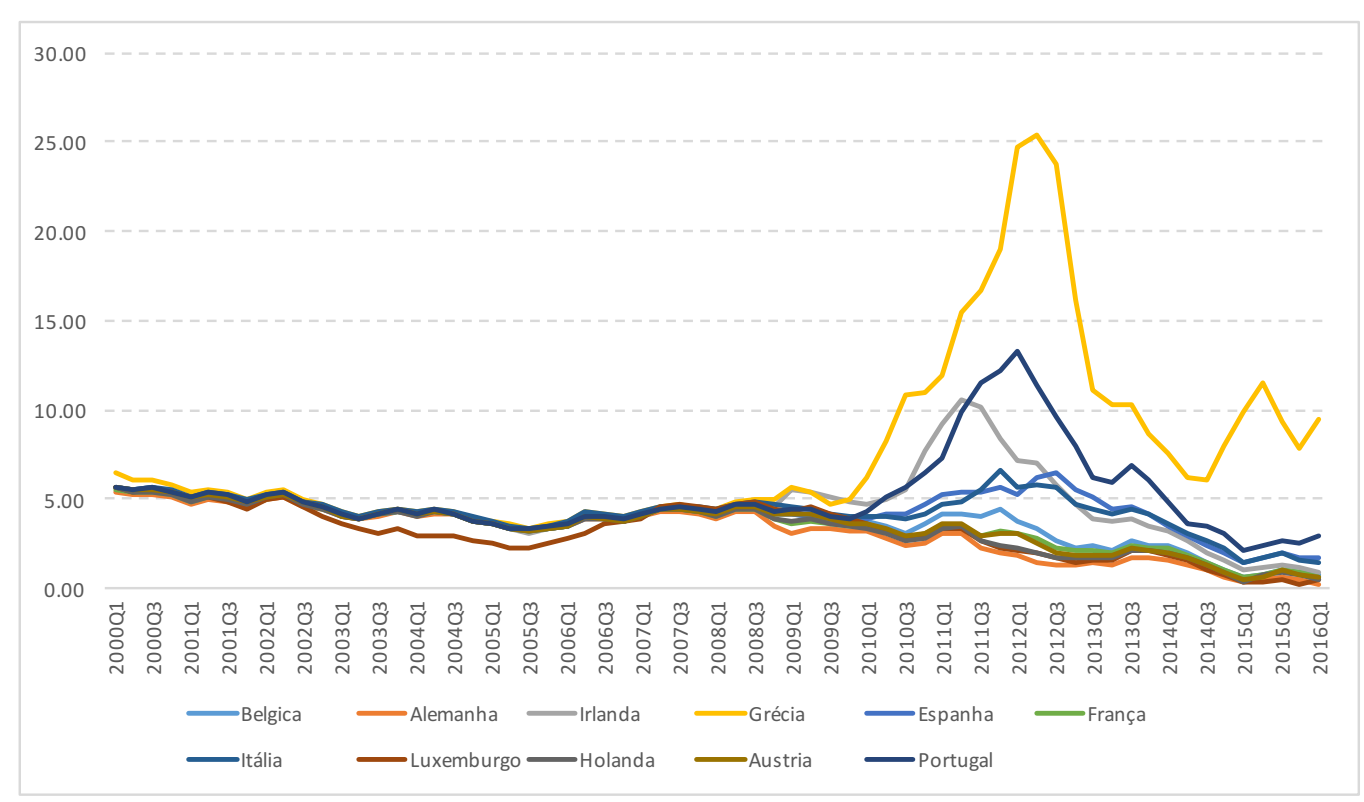

Fonte: Elaborado pela autora. Dados do Eurostat.

Apesar de a Grécia ser o caso mais evidenciado, a primeira fase da crise na Europa começou com a Irlanda e se iniciou como um desdobramento da crise financeira americana de setembro de 2008.

O crescimento da economia irlandesa estava bastante ancorado ao crescimento imobiliário. Com o advento da crise americana, estourou a bolha imobiliária na Irlanda, o que levou os preços dos imóveis a caírem mais de $50 \%$ em poucos meses. 
Os bancos irlandeses estavam com a carteira de crédito repleta de empréstimos a construtoras, o que transferiu o problema para o sistema financeiro irlandês. Para evitar a falência do sistema financeiro nacional, a Irlanda teve que garantir os compromissos dos bancos, ao mesmo tempo em que a arrecadação do país com impostos decrescia em função da crise econômica (Baselga-Pascual et al, 2015, p. 141).

Apelidada de "tigre celta", a Irlanda passou do crescimento acelerado ao colapso financeiro em um período de apenas três anos. A crise irlandesa, rapidamente, contagiou países europeus com economias mais frágeis, como Portugal, Itália, Grécia e Espanha, países periféricos europeus que passaram por substanciais instabilidades em suas economias, e, nesse contexto, foi cunhado o acrônimo PIIGS.

Irlanda e Espanha sofreram, majoritariamente, por conta da crise hipotecária combinada com crise financeira. Grécia, Itália e, em menor amplitude, Portugal viram suas economias diminuírem substancialmente por conta da crise, o que evidenciou o problema da dívida pública.

Em 2012, o então presidente da Comissão Europeia, José Manuel Durão Barroso, identificou as três maiores causas para a crise europeia:

- Dívida pública insustentável: endividamento desproporcional à capacidade de pagamento, sobretudo dos países periféricos.

- Diferenças em competitividade entre Estados-membros: no regime de câmbio fixo, com inflação superior à dos países centrais, os PIIGS tiveram um aumento do câmbio real, tornando-se pouco competitivos nas trocas internacionais.

- Práticas irresponsáveis do setor financeiro: os bancos europeus estavam expostos ao problema do subprime com importantes ativos em carteira; além disso, em alguns países, os bancos também tinham políticas de crédito extremamente expansivas, e, no momento da crise, sofreram com empréstimos que não estavam sendo pagos pelos bancos nacionais.

De acordo com Breuss (2015, p. 14), o custo econômico e social da crise europeia foi distribuído desigualmente entre os Estados-membros, e os países 
periféricos sofreram mais em termos de perda de PIB, desemprego e aumento da dívida pública.

O impacto desigual entre os Estados-membros fez com que a Europa se dividisse entre o menos bem-sucedido Sul e o mais bem-sucedido Norte.

\subsubsection{SOCORRO FINANCEIRO E PERSPECTIVAS DE LONGO PRAZO}

Em maio de 2010, os Ministros das Finanças dos países da União Europeia concordaram com a criação de um fundo de intervenção de 750 bilhões de Euros para estabilizar a zona Euro.

A Irlanda pediu assistência financeira do fundo de resgate europeu e do Fundo Monetário Internacional (FMI) em novembro de 2010, recebendo um empréstimo emergencial de 68 bilhões de Euros. O Anglo Irish Bank foi estatizado em janeiro de 2009, junto com diversos outros bancos. Um programa de austeridade foi introduzido pelo governo, com o monitoramento de Bruxelas. Benefícios sociais foram reduzidos, e os impostos subiram para auxiliar a reequilibrar as contas públicas.

Com a finalidade de restaurar a confiança no mercado financeiro europeu, em 2012, as autoridades europeias concordaram com a criação de uma união bancária, determinando regras comuns a todas as instituições financeiras europeias para estabelecer requerimentos de capitais mais adequados, maior proteção aos detentores de depósitos europeus e mecanismos de monitoramento do sistema financeiro mais eficazes.

A crise da dívida europeia chamou a atenção de todo o mundo para a questão fiscal da zona monetária única e, desde então, tem sido debatida a necessidade de reforçar as regras de gestão do Euro e de impor um mecanismo sancionatório para o cumprimento do Pacto de Estabilidade e Crescimento. 


\subsection{O PREÇO DO RISCO DE CRÉDITO SOBERANO}

O risco de default, ou risco de crédito, é a possibilidade, esperada pelo mercado, de um determinado devedor deixar de honrar suas obrigações financeiras. Standard \& Poor's (1998) definem default como o não cumprimento de uma obrigação de pagar, juros ou principal, na data especificada pelos termos originais da emissão da dívida.

Um default soberano é uma situação extrema, e mesmo pequenas variações na percepção de risco de default de um determinado país são rapidamente captadas pelo mercado e refletem na precificação dos bônus dos países.

O prêmio de risco, ou o spread de crédito, é uma medida de risco de crédito que reflete esse sentimento do mercado. Ele é medido pela diferença no yield entre títulos de mesma maturidade versus um título tido como "âncora", ou risk-free (livre de risco). O prêmio de risco traduz a rentabilidade adicional que um investidor requer para investir em um determinado título, dado seu risco.

A habilidade de um país honrar sua dívida afeta sua probabilidade de default e, portanto, o prêmio de risco que o país tem de pagar ao mercado para captar mais dinheiro.

\subsection{AS AGÊNCIAS DE RATING}

Uma agência de classificação de risco de crédito é uma empresa que, por solicitação de um ou vários clientes, qualifica determinados ativos financeiros ou devedores (países, governos ou empresas) segundo o grau de risco de default. $O$ setor de classificação de risco é formado por um oligopólio com três empresas: a Fitch, a Moody's e a Standard \& Poor's.

A avaliação da qualidade creditícia de cada governo soberano é quantitativa e qualitativa. Os aspectos quantitativos incluem várias medidas de desempenho econômico e financeiro, bem como as obrigações contingenciais, embora o julgamento sobre a integridade desses dados seja uma questão mais qualitativa. Tal 
análise é também qualitativa por causa da importância dos desdobramentos políticos e das políticas adotadas pelos governos soberanos.

Em linhas gerais, podemos destacar dez categorias que influenciam a estrutura analítica dos ratings soberanos: risco político, renda e estrutura econômica, perspectiva de crescimento econômico, flexibilidade fiscal, carga da dívida do governo, passivos contingenciais e, no exterior, estabilidade monetária, liquidez externa, carga do endividamento externo do setor público, carga do endividamento externo do setor privado.

A classificação de risco aferida pelas agências é baseada na sua expertise e em informações relevantes que podem ser públicas ou provenientes de sua análise.

Cada agência de classificação de risco possui metodologia e critérios próprios, entretanto, em termos gerais, podemos afirmar que, quanto maior for a probabilidade de default do agente, pior será a sua nota ou a sua classificação. Apesar de publicarem, genericamente, os indicadores utilizados na avaliação dos riscos em cada relatório emitido, as agências não divulgam seus critérios de análise dos fatores quantitativos e qualitativos nem os pesos que cada indicador tem na composição da nota de crédito emitida.

A Standard \& Poor's, por exemplo, centra-se em uma série de fatores econômicos, administrativos, no sistema de financiamento e na situação orçamental e financeira para definir o rating (Bellver \& Fernandez de Heredia, 2005).

Entre os fatores econômicos, são considerados:

- Demografia: tamanho em área absoluta, densidade demográfica, taxa de crescimento populacional, pirâmide etária e distribuição da população pelo território.

- Estrutura econômica: características de mão de obra, distribuição por setor econômico, nível de emprego e renda per capita.

- Perspectivas de crescimento: tendências sobre nível de emprego, produção e investimento.

Entre os fatores administrativos, são considerados: 
- Estrutura intergovernamental: existência de transferências intergovernamentais e sua expressão sobre a economia

- Equilíbrio entre receitas e gastos: capacidade de arrecadação, proporção do orçamento que não está sujeita a previsão e capacidade de financiamento.

- Sistemas e políticas de administração: consistência e rigor das políticas orçamentárias, qualidade dos informes financeiros, capacidade de resposta rápida do governo.

Entre os fatores de flexibilidade fiscal e execução orçamentária, a S\&P considera:

- Fontes de ingresso e sua flexibilidade: avaliação da estrutura de receitas e potencial para gerar maiores ingressos.

- Gastos e tendências: análise da composição dos gastos, vontade política de reduzir gastos, evolução dos gastos em períodos de crise.

- Execução orçamental e necessidade de financiamento: desvios entre as projeções orçamentais e os resultados finais, ritmo de acumulação de dívida em relação aos recursos disponíveis para amortização.

Entre os fatores financeiros, são considerados:

- Tesouraria: grau de adequação de ativos líquidos do governo para fazer frente aos compromissos de curto prazo. Analisam-se também o nível médio e mínimo de reservas e saldos em caixa em relação aos gastos totais e ao serviço da dívida.

- Volume de endividamento: serviço anual da dívida e nível total de dívida no final de ano versus recursos disponíveis. A análise do endividamento ainda inclui estrutura da dívida, vencimento, moeda e sensibilidade a taxas de juros.

- Outras obrigações financeiras não incluídas no orçamento: a análise de ativos contingentes, a dívida total do setor público, incluindo todas as empresas públicas e outras obrigações contingentes, bem como a probabilidade de que o governo tenha de honrar as garantias prestadas e a necessidade de sanear empresas públicas. 
Diversas críticas são atribuídas às agências de rating, entre elas, o fato de que os ratings são emitidos, geralmente, a pedido do emissor de títulos, que é quem paga a agência de rating, o que poderia gerar um conflito de interesses.

Historicamente, podemos listar diversos momentos em que as agências de rating não cumpriram seu papel de informar corretamente os investidores sobre o nível de risco atribuído aos emissores e às emissões, atenuando o risco em seus pareceres. Exemplos disso são os colapsos financeiros da Enron (2001), da WorldCom (2002), da Parmalat (2003), do Banco Santos (2004) e, talvez o mais famoso de todos, a crise americana do subprime (2008), quando as agências de risco informavam, em seus pareceres, que os ativos eram grau de investimento em um dia e, no momento seguinte, era anunciado o default dos papéis.

Apesar das críticas, as agências ainda são uma fonte importante de informação de crédito para o mercado financeiro. Elas estão permanentemente reavaliando os ratings atribuídos aos agentes, e, quando precisam reclassificar tal qualidade do crédito, elas anunciam a mudança ao mercado, gerando impactos importantes nos ativos emitidos por aquele agente, influenciando a percepção de risco, sua demanda e sua oferta ao mercado.

\subsection{VARIÁVEIS ECONÔMICAS E O RISCO DE CRÉDITO DOS PAÍSES}

Existe uma ampla literatura que trata da interação de variáveis econômicas e financeiras com a capacidade de endividamento dos países e, por consequência, o impacto dessas variáveis no risco de crédito soberano.

Curvas de juros, spreads de crédito, credit default swaps (ou derivativos de crédito) e notas de crédito soberano emitidas por agências de risco foram algumas das variáveis dependentes utilizadas pelos autores nos modelos de precificação de risco de crédito.

Por meio da análise das curvas de juros de diferentes países europeus, Lemmen \& Goodhart (1999) concluíram que o montante da dívida, a receita fiscal, a 
inflação e a volatilidade da inflação são variáveis significantes para determinar o risco de crédito soberano.

Bernoth et al. (2006), também trabalhando com países europeus, encontraram que o nível de endividamento, a magnitude do déficit fiscal, o pagamento de juros e amortizações da dívida e variáveis financeiras do mercado têm alto poder explicativo na precificação do prêmio de risco dos países europeus.

Faini (2006) estudou o impacto das mudanças no estoque de dívida pública e no superávit primário do prêmio de risco de 11 países europeus. De acordo com sua pesquisa, cada diminuição de $1 \%$ no superávit primário da zona faz com que as taxas de juros de longo prazo aumentem em 41 pontos-base, e, além disso, aumentos no estoque da dívida da zona em relação ao PIB impactam as taxas de juros de longo prazo dos títulos de países com relação dívida/PIB maior que 1.

Pan \& Singleton (2008) estudaram a relação entre o CDS de Coreia, México e Turquia, de 2001 a 2006, e variáveis econômicas globais, e concluíram que existe uma forte correlação entre o CDS e fatores de risco global, como CBOE VIX index, retorno de 10 anos de títulos corporativos BB, T-Bill de 6 meses e volatilidade das opções de câmbio da moeda do país em questão.

Analisando os determinantes do rating de crédito, Powell \& Martinez (2008) verificaram que variáveis de fundamento econômico são importantes para a determinação da nota de crédito soberano e, em contrapartida, variáveis de mercado têm baixa influência.

Em um trabalho de 2010, Arghyrou \& Kontonikas encontraram uma mudança no comportamento dos preços dos títulos europeus. Os pesquisadores concluíram que, até 2007, os preços dos títulos de dívida de longo prazo dos países da União Europeia eram convergentes e tinham pouca variação de spread; após 2017, os fundamentos econômicos e o risco internacional passam a exercer maior peso na formação dos preços. A pesquisa aponta, ainda, para o contágio entre os países após o default da Grécia, em novembro de 2009.

No trabalho de Caceres et al. (2010), os autores perceberam que o modelo de precificação dos spreads dos CDS responde a variáveis diferentes ao longo de um 
ciclo de crise. Os autores sugerem que fatores de risco global têm maior expressão no início das crises, enquanto que fatores de crédito país-específicos têm maior relevância.

Hilscher \& Nosbusch (2010) estudaram os efeitos dos fundamentos macroeconômicos na determinação do prêmio de risco de crédito para mercados emergentes e constataram que a volatilidade nos termos de troca é muito relevante para essa determinação.

Utilizando abordagem bayesiana para verificar o poder preditivo de variáveis macroeconômicas e financeiras na determinação do prêmio de risco de crédito dos países da zona do Euro, Maltritz (2012) observou que o montante da dívida, o saldo do comércio exterior e variáveis financeiras de liquidez e apetite de risco globais se mostraram significantes.

Beirne \& Fratzscher (2013) também encontraram evidências de que ocorreu um aumento significativo na sensibilidade do mercado financeiro aos fundamentos macroeconômicos durante a crise europeia; essa sensibilidade exacerbada derivou num aumento substancial dos yields soberanos e dos spreads dos CDS, não só dos países da Europa como globalmente.

Utilizando variáveis macroeconômicas projetadas, Clark \& Kassimatis (2015) propuseram um modelo para explicar a variação dos prêmios de risco soberanos. De acordo com o modelo, as variáveis macroeconômicas projetadas explicam $41 \%$ da variação dos prêmios de risco, sugerindo que as expectativas dos investidores refletidas nas variáveis projetadas teriam grande impacto na formação dos preços dos títulos soberanos.

Kriz et al. (2015) estudaram as principais variáveis econômicas e financeiras que impactam a capacidade de crédito dos países utilizando uma estatística de probabilidade acumulada de default. Os pesquisadores consideraram que o serviço da dívida, o crescimento do PIB, a nota de crédito emitida pelas agências de rating e o superávit primário são variáveis relacionadas à probabilidade de default.

Amstad et al. (2016) analisaram retornos mensais do CDS de 28 países, entre janeiro de 2004 e dezembro de 2014, e perceberam uma mudança estrutural no 
modelo pós-crise de 2008. Os autores verificaram que um fator de risco global único respondia por metade da variação dos retornos antes de 2008, e, após a crise, esse fator se tornou ainda mais relevante.

Silvapulle et al. (2016), pesquisando os spreads soberanos de Portugal, Itália, Irlanda, Grécia e Espanha, encontraram resultados de que o retorno do índice de bolsa alemão, o retorno do S\&P 500, o índice VIX e o rating da dívida soberana internacional têm significativa influência na formação de preço dos títulos dos países PIIGS e na volatilidade desses preços.

Caporale et al. (2017) analisaram os efeitos da publicação de notícias econômicas nos jornais com o spread soberano de 8 países da zona Euro com relação à Alemanha, no período de 1999 a 2014. Os pesquisadores encontraram evidências de que notícias negativas têm impacto significativo nos spreads para todos os países PIIGS (Portugal, Irlanda, Itália, Grécia e Espanha), e que a sensibilidade é maior no período da crise europeia.

Afonso \& Silva (2017) estudaram as variáveis que impactaram a evolução dos preços dos bônus soberanos de Portugal e Irlanda e encontraram evidências de que o yield dos bônus portugueses é impactado pelo yield dos bônus alemães, e também está relacionado com taxa de juros Euribor de 3 meses e com o nível de endividamento público.

Estudando a relação entre fatores macroeconômicos, variáveis financeiras globais e o spread de crédito de 27 países da OCDE, Ordoñez-Callamand et al. (2017) encontraram em sua pesquisa indicações de que fatores financeiros globais comuns são as principais variáveis, impactando o risco de solvência desses países, e que não são relevantes as variáveis macroeconômicas país-específicas. 
Tabela 3 - Quadro resumo referencial teórico

\begin{tabular}{|c|c|c|c|}
\hline Ano & Autores & Países & Variáveis relevantes \\
\hline 1999 & Lemmen \& Goodhart & Países europeus & Dívida, receita fiscal, inflação e volatilidade da inflação \\
\hline 2006 & Bernoth et al. & Países europeus & $\begin{array}{l}\text { dívida, déficit fiscal, pagamento de juros e amortizações da } \\
\text { divida e variáveis financeiras }\end{array}$ \\
\hline 2006 & Faini & Países europeus & dívida, superavit primario \\
\hline 2008 & Pan \& Singleton & $\begin{array}{l}\text { Coreia, Mexico e } \\
\text { Turquia }\end{array}$ & $\begin{array}{l}\text { VIX, retorno de } 10 \text { anos de títulos corporativos BB, T-Bill de } \\
6 \text { meses e volatilidade das opções de cambio }\end{array}$ \\
\hline 2008 & Powell \& Martinez & Paises emergentes & PIB, inflaçao e balanço fiscal \\
\hline 2010 & Arghyrou \& Kontonikas & Países europeus & fatores de risco internacional, contagio \\
\hline 2010 & Caceres et al. & diversos & $\begin{array}{l}\text { fatores de risco global no periodo pre-crise e depois disso } \\
\text { fatores de risco país-especifico }\end{array}$ \\
\hline 2010 & Hilscher \& Nosbusch & Paises emergentes & volatilidade nos termos de troca \\
\hline 2012 & Maltritz & Países europeus & $\begin{array}{l}\text { dívida, o saldo do comércio exterior, e variáveis financeiras } \\
\text { de liquidez e apetite de risco globais }\end{array}$ \\
\hline 2013 & Beirne \& Fratzscher & diversos & dívida, PIB, balanço fiscal e VIX \\
\hline 2015 & Clark \& Kassimatis & diversos & variáveis macroeconomicas projetadas \\
\hline 2015 & Kriz et al. & diversos & $\begin{array}{l}\text { serviço da divida, PIB, rating de credito e o superávit } \\
\text { primário }\end{array}$ \\
\hline 2016 & Amstad et al. & diversos & fator de risco global \\
\hline 2016 & Silvapulle et al. & $\begin{array}{l}\text { Portugal, Itália, } \\
\text { Irlanda, Grécia e } \\
\text { Espanha }\end{array}$ & $\begin{array}{l}\text { retorno do índice de bolsa alemão, o retorno do S\&P } 500 \text {, o } \\
\text { índice VIX e o rating de credito }\end{array}$ \\
\hline 2017 & Caporale et al. & Países europeus & noticias sobre economia \\
\hline 2017 & Afonso \& Silva & Portugal e Irlanda & yield dos bonos alemães, Euribor de 3 meses e dívida \\
\hline 2017 & Ordoñez-Callamand et al. & diversos & fatores de risco global \\
\hline
\end{tabular}




\section{METODOLOGIA}

\subsection{METODOLOGIA DE PESQUISA}

Segundo Gil (2007), quanto aos objetivos, a pesquisa pode ser classificada como exploratória, explicativa ou descritiva.

A pesquisa exploratória visa informar sobre o objeto estudado para orientar a formulação de hipóteses. Muitas descobertas científicas são resultado de pesquisas exploratórias.

De acordo com Lakatos \& Marconi (2011), a pesquisa explicativa, em contrapartida, estuda fenômenos e objetos já conhecidos e visa ampliar generalizações para definir modelos teóricos. Nesse tipo de pesquisa, os fatos são registrados e analisados com o objetivo de estabelecer uma relação de causalidade.

A pesquisa descritiva, atualmente uma das mais utilizadas nas indagações das ciências sociais, tem como objetivo a análise das variáveis que se relacionam com o fenômeno estudado. Nesse tipo de estudo, realizam-se o registro, a análise e a interpretação dos fatos do mundo sem a interferência do pesquisador.

Diehl \& Tatim (2004) determinam que a pesquisa pode ser de natureza quantitativa ou qualitativa, conforme a abordagem dos dados.

A pesquisa quantitativa se caracteriza pelo emprego da quantificação, tanto na coleta dos dados, como no tratamento e na interpretação destes, utilizando técnicas estatísticas.

Já a pesquisa qualitativa trabalha, predominantemente, com dados qualitativos, não envolvendo a quantificação dos fenômenos, mas sim sua descrição; difere da pesquisa quantitativa por não empregar instrumental estatístico para análise do problema em estudo.

Gil (2007) determina, ainda, que, de acordo com o procedimento técnico utilizado, a pesquisa pode ser classificada da seguinte maneira: 
a) Documental: baseada em material que não recebeu tratamento analítico. Gil (2007) define "dados primários" como aqueles que não receberam nenhum tratamento analítico, como documentos oficiais, contratos, fotografias, etc.; e "dados secundários" são definidos como os que, de alguma forma, já foram analisados, por exemplo, relatórios de pesquisa, relatórios de empresas, tabelas estatísticas, etc.

b) Bibliográfica: elaborada com base em material já publicado, como livros, revistas, artigos científicos, jornais, internet, etc.;

c) Experimental: fundamentada na determinação de um objeto de estudo e na observação das variáveis que o influenciam, em ambiente experimental;

d) Levantamento: efetuada por meio de questionamento direto a um grupo de pessoas cujo comportamento se deseja estudar;

e) Estudo de caso: realizada mediante estudo profundo e exaustivo de um determinado indivíduo ou grupo, de maneira que se permita o conhecimento detalhado dos aspectos do caso;

f) Pesquisa ex-post-facto: feita quando o experimento se realiza depois dos fatos;

g) Pesquisa-ação: concebida e realizada para a solução de um problema coletivo. Os pesquisadores participantes estão envolvidos de modo cooperativo ou participativo na pesquisa;

h) Pesquisa participante: caracterizada pela interação entre os pesquisadores em situações de pesquisa similares;

i) Pesquisa de campo: baseada na observação de fatos e fenômenos espontâneos.

A pesquisa apresentada neste trabalho é de natureza descritiva, uma vez que tem o objetivo de determinar as variáveis macroeconômicas e financeiras que estão relacionadas com a precificação dos títulos de dívida soberanos dos países participantes da zona Euro. Este trabalho é também uma pesquisa quantitativa, visto 
que utilizamos técnicas estatísticas para tratar dados primários dos países e mercados estudados; o procedimento técnico utilizado é documental.

A metodologia aplicada neste estudo segue o método científico com os passos propostos por Takeshy \& Mendes (2006): definição do problema, formulação das hipóteses, raciocínio dedutivo, por meio da revisão literária, da coleta de dados e da interpretação dos resultados, com rejeição ou não das hipóteses.

\subsection{HIPÓTESES DE PESQUISA}

De Grauwe \& Ji (2013) testaram a hipótese de que, depois da crise europeia, o mercado de dívida soberana europeia passou a ser mais influenciado pelo sentimento de aversão ao risco global. Os pesquisadores afirmam que o aumento nos prêmios de risco dos títulos da zona Euro, no período de 2010-11, está desconectado dos fundamentos econômicos, sugerindo que a situação econômica global, refletida numa variável binária de tempo, seria estatisticamente mais relevante para a formação de preço dos títulos do que variáveis macroeconômicas individuais.

Os autores em referência encontraram indícios de que os aumentos no nível de endividamento ou a deterioração da situação fiscal dos países não seriam estatisticamente significantes para explicar a correção de preços dos ativos.

No presente estudo, partimos das mesmas variáveis estudadas por De Grauwe \& Ji (2013), com o objetivo de validar se os fundamentos macroeconômicos efetivamente têm um papel secundário na formação dos preços dos títulos europeus e se existe alguma ruptura no modelo de formação de preços após a crise econômica europeia.

Dessa forma, temos como hipóteses de pesquisa:

Hipótese 1: as variáveis macroeconômicas selecionadas são estatisticamente significativas para o modelo de formação do preço da dívida soberana europeia.

Hipótese 2: as variáveis financeiras selecionadas são estatisticamente significativas para o modelo de formação do preço da dívida soberana europeia. 
Hipótese 3: houve uma ruptura no modelo de formação de preço dos títulos soberanos europeus no período pré e pós-crise europeia.

\subsection{AMOSTRA}

Utilizamos dados trimestrais para os 12 países europeus que formavam o bloco em janeiro de 2001, no período de janeiro de 2001 a junho de 2014, tomando-se a Alemanha como país-âncora.

\subsection{DEFINIÇÃO DAS VARIÁVEIS}

A literatura define "variáveis internacionais" como aquelas associadas ao nível de aversão ao risco do mercado, e "variáveis país-específico" como potenciais determinantes do prêmio de risco de crédito dos títulos soberanos de países europeus (Costantini et al., 2014, p. 337). A maior parte das variáveis testadas na literatura mensuram a sustentabilidade da dívida governamental.

Neste trabalho, como medida de risco de crédito soberano, variável dependente, utilizamos o prêmio de risco dos bônus de 10 anos com relação à Alemanha. O spread foi calculado com base no yield médio dos bônus de 10 anos de cada país, divulgado pelo Eurostat, utilizando a Alemanha como país-âncora, ou seja, as taxas de juros da Alemanha foram consideradas como taxas livres de risco para a zona Euro.

Parte dos pesquisadores relata as variáveis independentes diferenciadas de um país-âncora, no nosso caso, a Alemanha. Essa abordagem assume que o paísâncora não é, necessariamente, livre de risco; portanto, as variáveis independentes país-específico não podem ser tomadas sem a necessária diferenciação. Uma segunda vertente de pesquisadores utiliza as variáveis independentes puras, e, implicitamente, assume que o país-âncora é livre de risco, ou, pelo menos, que a taxa de juros do país-âncora é a melhor estimativa da taxa de juros livre de risco (Maltritz, 2012, p.664). 
Para ser consistente com a maior parte da literatura sobre o tema, foi escolhido trabalhar com as variáveis independentes, sem diferenciação com relação à Alemanha nesta pesquisa; apenas a variável dependente, o prêmio de risco de crédito, é calculada a partir do yield do título alemão.

A principal variável financeira que testamos é a alavancagem ou o montante da dívida com relação ao PIB. Diversos autores relatam a associação entre o montante da dívida e o prêmio de risco de crédito soberano (Lemmen \& Goodhart, 1999; Faini, 2006; Bernoth et al., 2006; Hallerberg \& Wolff, 2008; Maltritz, 2012). Um maior endividamento em relação ao PIB, intuitivamente, representaria um maior risco de crédito e, consequentemente, maior prêmio de risco com relação ao país-âncora.

Como a União Europeia é uma zona de regime de câmbio fixo entre os países, os quais utilizam a moeda única, a taxa de câmbio real efetiva entre os EstadosMembros capta o diferencial da inflação. A taxa de câmbio efetiva é calculada a partir da média ponderada dos índices de taxas de câmbio bilaterais, em que os pesos refletem a importância relativa de cada moeda nas trocas comerciais internacionais do bloco europeu.

A taxa de câmbio efetiva real conjuga os efeitos das trocas comerciais com os diferenciais de inflação de cada país-membro. Quando o câmbio nominal não se altera, o país que tem maior inflação experimenta uma apreciação real, diminuindo sua competitividade nas trocas entre países da zona de moeda comum e com o resto do mundo, o que pode levá-lo a possíveis déficits e problemas de endividamento (De Grauwe \& Ji, 2012: p.21). Investidores podem requerer um prêmio de risco para comprar dívida soberana desses países.

De acordo com a teoria econômica, o crescimento real do PIB afeta a capacidade de arrecadação e, consequentemente, de pagamento do país. Países em crescimento têm maior capacidade financeira, enquanto países em recessão podem ter problemas em honrar seus compromissos. O crescimento econômico ainda traz um componente preditivo para a arrecadação nos anos vindouros, sendo uma variável bastante popular na economia. 
Além das variáveis específicas de cada país, algumas variáveis relacionadas às condições globais também são reportadas como relevantes na literatura. $A$ taxa de juros dos títulos americanos de 10 anos, ou Treasury Rate, e a volatilidade do mercado acionário americano, ou Vix, são consideradas em diversas pesquisas para mensurar o nível de incerteza global e a aversão ao risco agregada.

Arghyrou \& Kontonikas (2010) encontraram que o fator de risco internacional, mesurado pela Treasury e pelo Vix, e um fator país-específico, representado pela competitividade internacional, são os principais fatores que contribuem para a precificação do prêmio de risco soberano durante as crises financeiras.

A Tabela 4, a seguir, resume as variáveis incluídas neste estudo.

Tabela 4 - Definição das variáveis

\begin{tabular}{|c|c|c|c|c|}
\hline & No. & Variável & Definiçao & Fonte \\
\hline Variável dependente & 0 & Sovereign spread & $\begin{array}{l}\text { Spread de juros do titulo de } 10 \text { anos (ancorado pelo título } \\
\text { germânico de mesma maturidade) }\end{array}$ & Eurostat \\
\hline \multirow{5}{*}{ Variáveis independentes } & 1 & GDP & Taxa de crescimento anual do PIB real & Eurostat \\
\hline & 2 & Debt & Divida total em proporçao ao PIB & Eurostat \\
\hline & 3 & REER & Taxa de cambio real efetiva & Eurostat \\
\hline & 4 & Treasury & Taxa de juros dos titulos de 10 anos americanos & Bloomberg \\
\hline & 5 & $\operatorname{Vix}$ & $\begin{array}{l}\text { Medida oficial da volatilidade implícita das opções sobre } \\
\text { o índice S\&P } 500\end{array}$ & Bloomberg \\
\hline
\end{tabular}

Fonte: Elaborado pela autora.

Partimos, então, para a análise estatística descritiva dessas variáveis, sintetizada na Tabela 4. Notamos que o spread médio dos títulos dos países analisados foi de 1.15, com desvio-padrão overall de 2.71; a variação no tempo, variação within, é mais alta que a variação entre os países, between, o que é justificado pela grande abertura dos prêmios de risco no deflagrar da crise europeia.

O crescimento do PIB médio foi de 0.99, com grande amplitude overall, variando de -10.2 a 8.8 . 
O endividamento medido pela dívida total em proporção do PIB médio foi de 58.96, com desvio-padrão between de 23.22, o que demonstra que a diferença de endividamento entre os países analisados é grande e muito maior que a variação do endividamento de um determinado país ao longo do tempo, que é de 10.1. O mesmo vale para a taxa de câmbio real efetiva, que também teve variação between maior que a variação within.

Tabela 5 - Decomposição do desvio-padrão no Software Stata

\begin{tabular}{|c|c|c|c|c|c|c|}
\hline Variável & & Média & Desvio Padrao & Min & Max & Observaçoes \\
\hline \multirow[t]{3}{*}{ Tempo } & overall & 189.5 & 15.03 & 164 & 215 & $\mathrm{~N}=520$ \\
\hline & between & & 0 & 189.5 & 189.5 & $\mathrm{n}=10$ \\
\hline & within & & 15.03 & 164 & 215 & $\mathrm{~T}=52$ \\
\hline \multirow[t]{3}{*}{ Spread } & overall & 1.15 & 2.71 & -0.04 & 23.98 & $\mathrm{~N}=520$ \\
\hline & between & & 1.22 & 0.2 & 4.15 & $\mathrm{n}=10$ \\
\hline & within & & 2.45 & -2.84 & 20.98 & $\mathrm{~T}=52$ \\
\hline \multirow[t]{3}{*}{ GDP } & overall & 0.99 & 3.07 & -10.2 & 8.8 & $\mathrm{~N}=520$ \\
\hline & between & & 0.79 & -0.09 & 2.36 & $\mathrm{n}=10$ \\
\hline & within & & 2.98 & -10.66 & 7.89 & $\mathrm{~T}=52$ \\
\hline \multirow[t]{3}{*}{ Debt } & overall & 58.96 & 23.38 & 18.2 & 121.6 & $\mathrm{~N}=520$ \\
\hline & between & & 23.22 & 34.39 & 97.02 & $\mathrm{n}=10$ \\
\hline & within & & 10.1 & 37.64 & 94.07 & $\mathrm{~T}=52$ \\
\hline \multirow[t]{3}{*}{ REER } & overall & 100.05 & 2.29 & 92.62 & 108.22 & $\mathrm{~N}=520$ \\
\hline & between & & 1.15 & 97.82 & 101.64 & $\mathrm{n}=10$ \\
\hline & within & & 2.02 & 92.49 & 106.62 & $\mathrm{~T}=52$ \\
\hline
\end{tabular}

Fonte: Elaborado pela autora. Dados do Eurostat.

A fim de antecipar qualquer problema de correlação entre as variáveis, estimamos a tabela de correlação a seguir. De acordo com a Tabela 6, notamos que não há correlação expressiva entre as variáveis escolhidas, de modo que podemos passar para a análise econométrica. 
Tabela 6 - Matriz de correlação das variáveis

\begin{tabular}{l|cccccc} 
& Spread & GDP & Debt & REER & Tsy & VIX \\
\hline Spread & 1.00 & & & & & \\
GDP & -0.52 & 1.00 & & & & \\
Debt & 0.37 & -0.35 & 1.00 & & & \\
REER & 0.18 & -0.28 & 0.24 & 1.00 & 1.00 & 1.00 \\
Tsy & -0.50 & 0.54 & -0.28 & -0.06 & -0.15 &
\end{tabular}

Fonte: Elaborado pela autora. Dados do Eurostat.

\subsection{ANÁLISE ECONOMÉTRICA}

Este trabalho é composto de dois estudos. O primeiro estudo busca verificar a importância das variáveis macroeconômicas e financeiras na explicação da formação de preço do risco de crédito dos países da União Europeia, medido pelo prêmio de risco dos títulos soberanos de 10 anos com relação ao país-âncora, neste trabalho, a Alemanha.

O segundo estudo procura identificar se existe ruptura no modelo de formação de preço do risco de crédito dos países da União Europeia, baseando-se em uma análise temporal, utilizando variáveis binárias para identificar os períodos de crise.

A premissa do segundo estudo é que a ocorrência de crises poderia afetar o senso comum dos investidores, que passariam a valorizar diferentes variáveis daquelas utilizadas em períodos de normalidade. A justificativa para esse pressuposto está relacionada com o aumento da aversão de risco nos períodos de crise e seus possíveis desdobramentos para as decisões de investimento (Frank \& Hesse, 2009, p. 6).

Modelos de regressão para dados em painel são utilizados para estudar fenômenos que se alteram, simultaneamente, entre indivíduos e de forma temporal, já que permitem ao pesquisador trabalhar com dados em cross-section ao longo do tempo (Fávero, 2015, pg. 257). 
No nosso problema de pesquisa, trabalhamos com dados trimestrais de 12 países europeus, no período de janeiro de 2001 a junho de 2014, tomando-se a Alemanha como país-âncora.

Inicialmente, propusemos o modelo mais simples para precificação do prêmio de risco soberano apontado na literatura, representado por uma regressão linear para dados em painel (Edwards (1986), Eichengreen \& Mody (1998), Hilscher, J. \& Nosbusch, Y. (2010)):

\author{
Fórmula (1) \\ $y=\sum_{j=1}^{J} b_{j} x^{j}+e$
}

Onde:

y representa a variável dependente prêmio de risco soberano com relação à Alemanha;

$\mathrm{x}$ representa uma matriz das variáveis macroeconômicas e financeiras de dimensão J por 54;

b representa um vetor dos parâmetros estimados.

De Grauwe \& Ji (2013) e Aizenman, Hutchison, \& Jinjarak (2013) sinalizam que o aumento dos prêmios de risco dos títulos europeus, depois de 2010, não pode ser explicado por fundamentos macroeconômicos. Eles sugerem que o sentimento do mercado de aversão a risco global se tornou relativamente mais importante na formação dos preços dos títulos europeus e que os investidores não levaram em consideração as condições macroeconômicas dos países individualmente, mas que o momento econômico mundial, refletido numa variável binária de tempo, foi mais relevante. 
Nesta pesquisa, pretendemos analisar se as variáveis macroeconômicas efetivamente têm um efeito secundário nesse movimento de preços ou se são um vetor importante para a mudança no padrão dos prêmios de risco dos países europeus.

Para testar nossa hipótese, estimamos um modelo linear para dados em painel que permite uma variação na inclinação da reta a partir de 2010:

\section{Fórmula (2)}

$$
y=\sum_{j=1}^{J} b_{j} x^{j}+\sum_{j=1}^{J} d_{j} q^{*} x^{j}+e
$$

Onde:

y representa o prêmio de risco soberano com relação à Alemanha;

x representa uma matriz das variáveis macroeconômicas e financeiras de dimensão J por 54;

$q^{*}$ é a variável binária que tem valor 0 antes do primeiro trimestre de 2010 e 1 depois disso, que multiplica as variáveis macroeconômicas $\mathrm{x}$;

b são os impactos das variáveis macroeconômicas antes do primeiro trimestre de 2010;

d é o impacto incremental das variáveis macroeconômicas após o primeiro trimestre de 2010.

Os parâmetros $\mathbf{d}$ nos permitem analisar se houve mudança no padrão de formação de preços dos títulos europeus depois da recusa por parte da Alemanha em 
resgatar a Grécia, sendo que b+d são os respectivos impactos totais das $\mathrm{J}$ variáveis macroeconômicas depois do primeiro trimestre de 2010.

Neste trabalho, testamos se esses parâmetros b e d são, estatística e economicamente, importantes no modelo. 


\section{ANÁLISE DOS RESULTADOS}

\subsection{UMA QUEBRA NO MODELO}

A fim de comparar nossos resultados com a literatura, inicialmente estimamos um modelo linear de formação do preço dos prêmios de risco soberanos em função das variáveis macroeconômicas indicadas anteriormente: crescimento real do PIB, estoque de dívida pública em proporção ao PIB e taxa efetiva de câmbio.

Existem diversos modelos lineares para tratar dados em painel, e a principal diferença entre eles é a existência de efeitos fixos ou efeitos aleatórios. O modelo de efeitos fixos, também conhecido por estimação within, é usado quando a variância entre as observações dos indivíduos é maior no tempo do que na cross-section, enquanto que o modelo de efeitos aleatórios é usado quando a variância é maior na cross-section do que no tempo.

Para definir qual modelo aplicar ao nosso painel, a princípio, analisamos o comportamento da variância das variáveis. Para tanto, analisamos a variância total, between e within para as variáveis incluídas no modelo.

Conforme a Tabela 4, apresentada no capítulo 3, notamos que o prêmio de risco spread, o crescimento do pib real gdpreal e a taxa efetiva de câmbio reer dos países apresentam maior variação within, ou seja, maior variação no tempo, enquanto o estoque da dívida debt possui maior variação between, ou seja, maior variação na cross-section.

Esses dados podem ser melhor visualizados na Figura 3, a qual apresenta o comportamento das variáveis ao longo do tempo, por país. 
Figura 3 - Comportamento das variáveis do modelo ao longo do tempo
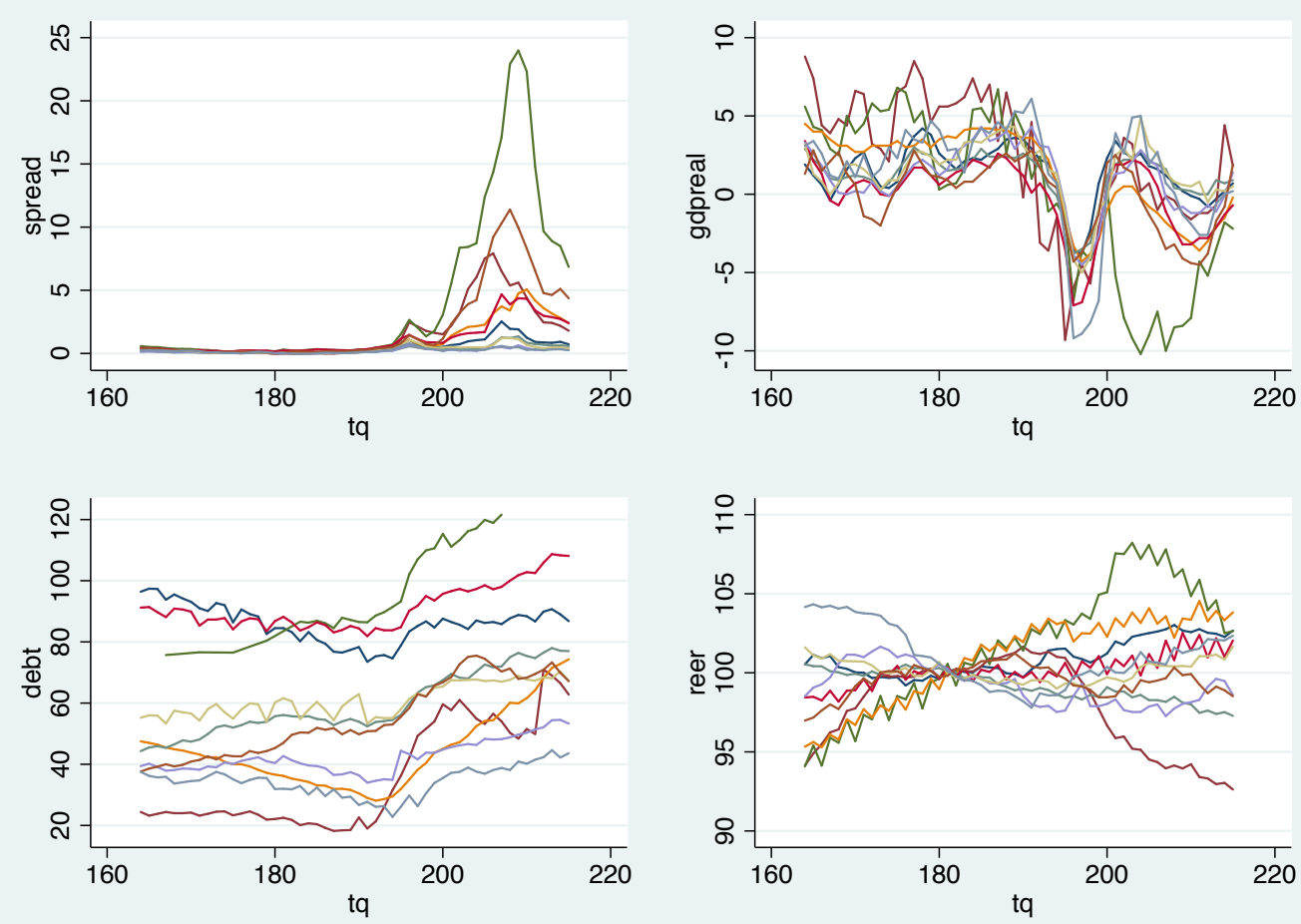

Fonte: Elaborado pela autora. Dados da Eurostat.

Como a variável dependente spread apresenta maior variação within, principalmente em razão da alta variabilidade dos spreads após a crise, quando há uma significativa abertura do prêmio de risco entre os países analisados, num primeiro momento, sugere-se a aplicação do modelo de efeitos fixos.

Para trazer mais consistência aos resultados, como outras variáveis independentes que apresentam variação between expressiva, optamos por estimar o modelo de efeitos fixos e o modelo de efeitos aleatórios e aplicar o teste de Hausman para verificar sua correta aplicação. 
O resultado do teste de Hausman nos indica que, com 95\% de confiança, podemos rejeitar a hipótese $\mathrm{H}_{0}$; desse modo, concluímos que o modelo de efeitos fixos é o mais apropriado. Os resultados do teste podem ser conferidos no Apêndice.

Chegamos, enfim, ao modelo linear de efeitos fixos, descrito a seguir:

$$
\begin{gathered}
\text { Modelo Linear } \\
\text { Spread }_{i t}=\propto_{i}+b_{1} G D P_{i t}+b_{2} D E B T_{i t}+b_{3} R E E R_{i t}+e_{i t}
\end{gathered}
$$

Inicialmente, os parâmetros estimados para as variáveis gpreal e debt tiveram os sinais esperados. Um incremento de $1 \%$ do estoque de dívida aumenta o prêmio de risco soberano em aproximadamente $0,1 \%$. O maior impacto é o do crescimento real do PIB, em que, para cada aumento de $1 \%$ no crescimento do PIB, temos uma redução de $0,15 \%$ no prêmio de risco.

De acordo com nossa proposta, acreditamos que exista uma ruptura no modelo de formação do preço do prêmio de risco de crédito após a crise de 2010. A fim de testar essa hipótese, estimamos o modelo Structural break (1) para o período completo, permitindo uma ruptura na inclinação no primeiro trimestre de 2010 . A equação resultante é a seguinte:

\section{Structural break (1)}

$$
\begin{aligned}
\operatorname{Spread}_{i t}= & \propto_{i}+b_{1} G D P_{i t}+b_{2} D E B T_{i t}+b_{3} \text { REER }_{i t}+d_{1} q^{*} G D P_{i t}+d_{2} q^{*} D E B T_{i t} \\
& +d_{3} q^{*} R E E R_{i t}+e_{i t}
\end{aligned}
$$


A volatilidade do S\&P, medida pelo índice Vix, e a taxa de juros americana, medida pela Treasury de 10 anos, foram incluídas num segundo momento, para captar mudanças no nível de aversão internacional ao risco e no nível internacional da taxa de juros. Chamamos esse modelo de Structural break (2):

\section{Structural break (2)}

$$
\begin{aligned}
\text { Spread }_{i t}=\propto_{i} & +b_{1} \text { GDP }_{i t}+b_{2} D E B T_{i t}+b_{3} \text { REER }_{i t}+b_{4} \text { Treasury }_{i t}+b_{5} \text { VIX }_{i t} \\
& +d_{1} q^{*} G D P_{i t}+d_{2} q^{*} D E B T_{i t}+d_{3} q^{*} \text { REER }_{i t}+d_{4} q^{*} \text { Treasury }_{i t} \\
& +d_{5} q^{*} \text { VIX }_{i t}+e_{i t}
\end{aligned}
$$

Depois da negação da Alemanha em resgatar a Grécia, no primeiro trimestre de 2010 , todas as variáveis macroeconômicas consideradas nesta análise se mostraram relevantes para explicar as variações no prêmio de risco soberano como vemos no modelo Structural break (2), sugerindo que os investidores passaram a considerar fundamentos macroeconômicos mais criteriosamente na formação do preço dos títulos de dívida europeus após a crise de 2010.

É importante ressaltar que a magnitude do impacto do crescimento do PIB na formação do preço do prêmio de risco é aumentada consideravelmente no período pós-crise, de -0,026 para -0,686, de acordo com o modelo Structural break (2).

O índice Vix, aceito no mercado financeiro como uma medida de aversão ao risco global, é estatisticamente significante no modelo Structural Break (2) após 2010, com sinal positivo, sugerindo que um aumento na aversão ao risco global impacta positivamente a formação do prêmio de risco de crédito. Caballero e Krishnamurthy (2008) e Krishnamurthy (2010) encontraram resultados similares em seus trabalhos, mostrando que, quando a aversão global ao risco aumenta, a demanda por ativos financeiros de maior risco diminui, o que impacta diretamente 
seus preços. Esse fenômeno é conhecido no mercado financeiro como flight-toquality.

Se os investidores realmente passaram a considerar os países periféricos europeus mais arriscados depois da recusa em resgatar os títulos gregos, o impacto das mudanças no Vix deveria ser maior após 2010 do que no período pré-crise.

Na verdade, nossos resultados mostram exatamente isto: mudanças no Vix só são estatisticamente significantes após 2010, mostrando que os investidores realmente mudaram sua percepção de risco com relação aos títulos europeus, considerando os países periféricos menos seguros depois disso.

Quando permitimos a ruptura no modelo após 2010 e controlamos pelas variáveis financeiras Treasury e Vix, obtemos uma melhora no R-quadrado, de 0.50 (Linear Model) para 0.76 (Structural break (2)).

Além disso, utilizamos o modelo autorregressivo de Arellano-Bond (1991), com a variável spread defasada. Nesse modelo, o efeito autorregressivo é muito expressivo, e as variáveis macroeconômicas e financeiras, objeto deste estudo, possuem um impacto de magnitude bastante reduzida.

Os resultados compilados estão expostos na Tabela 7. 
Tabela 7 - Modelo linear, Arellano-Bond, Structural break 1, Structural break 2

\begin{tabular}{|c|c|c|c|c|}
\hline & Linear & Arellano-Bond & Structural break (1) & Structural break (2) \\
\hline Spread L.1 & & $\begin{array}{r}0.9314 \\
(0.000)^{* * * *}\end{array}$ & & \\
\hline GDP & $\begin{array}{c}-0.1471 \\
(0.000)^{* * *}\end{array}$ & $\begin{array}{r}0.269 \\
(0.000)^{* * * *}\end{array}$ & $\begin{array}{c}-0.0598 \\
(0.000)^{* * * *}\end{array}$ & $\begin{array}{l}-0.0261 \\
(0.326)\end{array}$ \\
\hline DEBT & $\begin{array}{r}0.0978 \\
(0.000)^{* * *}\end{array}$ & $\begin{array}{l}0.0017 \\
(0.477)\end{array}$ & $\begin{array}{r}0.0449 \\
(0.000)^{* * * *}\end{array}$ & $\begin{array}{r}0.0506 \\
(0.000)^{* * * *}\end{array}$ \\
\hline REER & $\begin{array}{r}0.1281 \\
(0.000)^{* * * *}\end{array}$ & & $\begin{array}{l}-0.0430 \\
(0.128)\end{array}$ & $\begin{array}{l}-0.0390 \\
(0,128)\end{array}$ \\
\hline GDPd2010 & & $\begin{array}{c}-0.1135 \\
(0.000)^{* * *}\end{array}$ & $\begin{array}{c}-0.5692 \\
(0.000)^{* * * *}\end{array}$ & $\begin{array}{c}-0.6863 \\
(0.000)^{* * * *}\end{array}$ \\
\hline DEBTd2010 & & $\begin{array}{l}-0.0013 \\
(0.262)\end{array}$ & $\begin{array}{r}0.0209 \\
(0.000)^{* * * *}\end{array}$ & $\begin{array}{r}0.0194 \\
(0.000)^{* * *}\end{array}$ \\
\hline REERd2010 & & & $\begin{array}{l}0.0009 \\
(0.803)\end{array}$ & $\begin{array}{c}-0.0374 \\
(0.000)^{* * * *}\end{array}$ \\
\hline Treasury & & & & $\begin{array}{l}-0.0579 \\
(0.607)\end{array}$ \\
\hline Vix & & $\begin{array}{r}0.1564 \\
(0.000)^{* * * *}\end{array}$ & & $\begin{array}{l}0.0089 \\
(0.154)\end{array}$ \\
\hline Treasuryd 2010 & & & & $\begin{array}{c}0.3298 \\
(0.056)^{*}\end{array}$ \\
\hline Vixd2010 & & $\begin{array}{r}0.2322 \\
(0.000)^{* * * *}\end{array}$ & & $\begin{array}{r}0.1401 \\
(0.000)^{* * *}\end{array}$ \\
\hline _cons & $\begin{array}{c}-17.4913 \\
(0,000)^{* * *}\end{array}$ & & $\begin{array}{l}2.2340 \\
(0.453)\end{array}$ & $\begin{array}{l}1.5209 \\
(0.580)\end{array}$ \\
\hline R-sq within & 0.5058 & & 0.7000 & 0.7622 \\
\hline R-sq between & 0.2037 & & 0.3962 & 0.4211 \\
\hline R-sq overall & 0.1948 & & 0.5264 & 0.5556 \\
\hline
\end{tabular}

Fonte: Elaborado pela autora.

De Grauwe e Ji (2012) propuseram um modelo de formação de preço do prêmio de risco dos títulos europeus com uma ruptura no ano de 2007-2008, na grande crise do subprime. Para testar essa possibilidade, estimamos um modelo Structural Break (3) permitindo duas rupturas: uma em 2008, e outra em 2010. Entretanto, como podemos visualizar na Tabela 8 , as variáveis explicativas, multiplicadas pela variável binária do ano de 2008 , não se mostraram estatisticamente relevantes ao nível de $5 \%$ de significância. O resultado sugere que, efetivamente, o maior impacto ocorre, de fato, após 2010 . 
Tabela 8 - Resultados: Modelo Structural break 3

\begin{tabular}{|c|c|}
\hline & Structural break (3) \\
\hline \multirow[t]{2}{*}{ GDP } & -0.0441 \\
\hline & $(0.301)$ \\
\hline \multirow[t]{2}{*}{ DEBT } & 0.0499 \\
\hline & $(0.000)^{* * *}$ \\
\hline \multirow[t]{2}{*}{ REER } & -0.0446 \\
\hline & $(0.091)^{*}$ \\
\hline \multirow[t]{2}{*}{ GDPd2008 } & 0.0749 \\
\hline & $(0.222)$ \\
\hline \multirow[t]{2}{*}{ DEBTd2008 } & -0.0001 \\
\hline & $(0.979)$ \\
\hline \multirow[t]{2}{*}{ REERd2008 } & 0.0258 \\
\hline & $(0.256)$ \\
\hline \multirow[t]{2}{*}{ GDPd2010 } & -0.7449 \\
\hline & $(0.000)^{* * *}$ \\
\hline \multirow[t]{2}{*}{ DEBTd 2010} & 0.0203 \\
\hline & $(0.001)^{* * *}$ \\
\hline \multirow[t]{2}{*}{ REERd2010 } & -0.0595 \\
\hline & $(0.008)^{* * *}$ \\
\hline \multirow[t]{2}{*}{ Treasury } & 0.0756 \\
\hline & $(0.578)$ \\
\hline \multirow[t]{2}{*}{ Vix } & 0.0007 \\
\hline & $(0.935)$ \\
\hline \multirow[t]{2}{*}{ Treasuryd 2008} & -0.6776 \\
\hline & $(0.203)$ \\
\hline \multirow[t]{2}{*}{ Vixd2008 } & 0.0044 \\
\hline & $(0.077)^{*}$ \\
\hline \multirow[t]{2}{*}{ Treasuryd 2010} & 0.8755 \\
\hline & $(0.101)$ \\
\hline \multirow[t]{2}{*}{ Vixd2010 } & 0.1438 \\
\hline & $(0.000)^{* * *}$ \\
\hline \multirow[t]{2}{*}{ _cons } & 1.7047 \\
\hline & $(0.552)$ \\
\hline R-sq within & 0.7642 \\
\hline R-sq between & 0.4206 \\
\hline R-sq overall & 0.5569 \\
\hline
\end{tabular}

Fonte: Elaborado pela autora. 
Entretanto, todos os nossos resultados podem ser inválidos na presença de heterocedasticidade.

Aplicamos o teste de Pesaran para testar a presença de heterocedasticidade e concluímos que o modelo não é homocedástico; portanto, precisamos corrigi-lo.

Dessa maneira, aplicamos os erros-padrão de Driscoll e Kraay, que são robustos na presença de heterocedasticidade (Hoechle, 2007, p. 2).

Realizamos, ainda, o teste robusto de Hausman, específico para esses modelos, a fim de confirmar a preferência pelo modelo de efeitos fixos. Com base nos resultados, podemos rejeitar a hipótese nula ao nível de significância de $5 \%$, ou seja, o modelo proposto deve ser estimado por efeitos fixos. Os resultados do teste podem ser conferidos no Apêndice.

Na Tabela 9, mostramos que, mesmo no modelo robusto de efeitos fixos, os resultados se mantêm. Todas as variáveis macroeconômicas consideradas no modelo são estatisticamente significantes, a 10\% de significância, após 2010. O nível de aversão ao risco, medido pelo Vix, também tem seu impacto muito mais exuberante após a crise de 2010 .

Os resultados sugerem que, efetivamente, existe uma ruptura no modelo, após 2010, e que as condições macroeconômicas individuais de cada país e o nível de aversão ao risco global têm seu impacto aumentado após a recusa do resgate dos títulos gregos. 
Tabela 9 - Resultados robustos

\begin{tabular}{|c|c|c|}
\hline & Structural break (2) & $\begin{array}{c}\text { Structural break (2) } \\
\text { Robust } \\
\end{array}$ \\
\hline \multirow[t]{2}{*}{ GDP } & -0.0261 & -0.0261 \\
\hline & $(0.326)$ & $(0.375)$ \\
\hline \multirow[t]{2}{*}{ DEBT } & 0.0506 & 0.0506 \\
\hline & $(0.000)^{* * * *}$ & $(0.001)^{* * * *}$ \\
\hline \multirow[t]{2}{*}{ REER } & -0.0390 & -0.0390 \\
\hline & $(0,128)$ & $(0.405)$ \\
\hline \multirow[t]{2}{*}{ GDPd2010 } & -0.6863 & -0.6863 \\
\hline & $(0.000)^{* * *}$ & $(0.000)^{* 2 * 4}$ \\
\hline \multirow[t]{2}{*}{ DEBTd 2010} & 0.0194 & 0.0194 \\
\hline & $(0.000)^{* 2 * *}$ & $(0.095)^{*}$ \\
\hline \multirow[t]{2}{*}{ REERd2010 } & -0.0374 & -0.0374 \\
\hline & $(0.000)^{* * *}$ & $(0.002)^{* 2 * 4}$ \\
\hline \multirow[t]{2}{*}{ Treasury } & -0.0579 & -0.0579 \\
\hline & $(0.607)$ & $(0.585)$ \\
\hline \multirow[t]{2}{*}{ Vix } & 0.0089 & 0.0089 \\
\hline & $(0.154)$ & $(0.084)^{*}$ \\
\hline \multirow[t]{2}{*}{ Treasuryd 2010} & 0.3298 & 0.3298 \\
\hline & $(0.056)^{*}$ & $(0.083)^{*}$ \\
\hline \multirow[t]{2}{*}{ Vixd2010 } & 0.1401 & 0.1401 \\
\hline & $(0.000)^{* * *}$ & $(0.000)^{* * *}$ \\
\hline \multirow[t]{2}{*}{ _cons } & 1.5209 & 1.5209 \\
\hline & $(0.580)$ & $(0.734)$ \\
\hline R-sq & 0.7622 & 0.7672 \\
\hline
\end{tabular}

Fonte: Elaborado pela autora. 


\section{CONSIDERAÇÕES FINAIS}

É do interesse dos países controlar o prêmio de risco de crédito para diminuir seu custo de endividamento, assim como é de interesse dos investidores entender as variáveis que impactam o prêmio de risco soberano para tentar prever movimentos nos yields dos mercados de títulos e fazer melhores investimentos.

O caso europeu e os desdobramentos da crise de 2010 nos mercados de dívida das nações europeias é tema de estudos no meio acadêmico sobre o qual encontramos uma literatura extensa e extremante rica. Muitos estudos foram feitos para analisar as variáveis macroeconômicas e financeiras com poder preditivo na determinação do prêmio de risco de crédito soberano. Entretanto, os resultados são bem distintos, a depender das variáveis explicativas testadas e dos períodos analisados.

A diversidade dos resultados e a falta de consenso sobre quais variáveis são determinantes para a percepção do risco de crédito sugerem que o modelo pode sofrer ruptura ao longo do período.

Nossa contribuição está em testar se houve uma quebra estrutural no modelo de formação de preço do risco de crédito soberano europeu após a crise de 2010. Para a análise, trabalhamos com dados em painel, no período de janeiro de 2001 a junho de 2014, para os 12 países europeus que formavam o bloco em janeiro de 2001.

De acordo com o modelo escolhido, Structural break (2), no período de 2001 até o primeiro trimestre de 2010, a única variável macroeconômica relevante foi o endividamento, sugerindo que, até a crise europeia, os investidores não embutiam no prêmio de risco soberano os principais fundamentos macroeconômicos, como o crescimento do PIB. Após a Alemanha se opor a resgatar os títulos gregos, no início do ano de 2010, o modelo sofre uma quebra estrutural, e as variáveis macroeconômicas passam a ser relevantes na explicação do prêmio de risco de crédito soberano. 
Cabe enfatizar também que até a magnitude do impacto da variável "endividamento" é consideravelmente ampliada após o primeiro trimestre de 2010, sugerindo que os investidores passaram a olhar com mais critério para essa variável e que isso está refletido na formação do preço do título.

Corroborando nossa análise, ressaltamos que a variável Vix, que é uma medida da aversão ao risco amplamente aceita no mercado financeiro, também entra no modelo após 2010.

Os achados podem ter implicação prática nas estratégias de investimento, uma vez que investidores podem identificar desvios na precificação dos títulos em mercados de euforia e se proteger contra as possíveis correções em mercados de baixa por meio de instrumentos derivativos, ou de uma melhor diligência na formação das carteiras, escolhendo ativos com retorno compatível ao perfil de risco.

Tais achados também têm implicação na gestão da dívida dos países periféricos, uma vez que estes podem tirar proveito de emissões de dívida nova em momentos de mercado favorável, quando a taxa de retorno requerida pelo investidor é mais baixa do que a sugerida pelo perfil macroeconômico do país em momentos de crise. 


\section{REFERÊNCIAS}

Afonso, A., \& Silva, J. (2017). Debt crisis and 10-year sovereign yields in Ireland and in Portugal. Applied Economics Letters, 1-6.

Amstad, M., Remolona, E., \& Shek, J. (2016). How do global investors differentiate between sovereign risks? The new normal versus the old. Journal of International Money and Finance, 66, 32-48.

Aizenman, Joshua, Michael Hutchison, and Yothin Jinjarak. (2013) What is the risk of European sovereign debt defaults? Fiscal space, CDS spreads and market pricing of risk. Journal of International Money and Finance 34, 37-59.

Arellano M, Bond S. Some tests of specification for panel data: Monte Carlo evidence and an application to employment equations. The review of economic studies. 1991; 58 (2): 277-297.

Arghyrou, M. G., \& Tsoukalas, J. D. (2011). The Greek debt crisis: Likely causes, mechanics and outcomes. The World Economy, 34(2), 173-191.

Arghyrou, M., \& Kontonikas, A. (2010). The EMU sovereign-debt crisis: a call and an opportunity for a Greek supply-side revolution. Economics Section Cardiff Business School, Economics Department, University of Glasgow Business School.

Baselga-Pascual, L., Trujillo-Ponce, A., \& Cardone-Riportella, C. (2015). Factors influencing bank risk in Europe: Evidence from the financial crisis. The North American Journal of Economics and Finance, 34, 138-166.

Bellver, A., Fernandez de Heredia, M. (2005). Critérios y processos de decisión para definir um rating. CLM.Economía, 6, 155-169.

Beirne, J., \& Fratzscher, M. (2013). The pricing of sovereign risk and contagion during the European sovereign debt crisis. Journal of International Money and Finance, 34, 60-82. 
Bernoth, K., Von Hagen, J., \& Schuknecht, L. (2012). Sovereign risk premiums in the European government bond market. Journal of International Money and Finance, 31(5), 975-995.

Breuss, F. (2015). The Crisis in Retrospect: Causes, Effects and Policy Responses. Handbook of the Economics of European Integration, 1.

Caballero, R. J., \& Krishnamurthy, A. (2008). Collective risk management in a flight to quality episode. The Journal of Finance, 63(5), 2195-2230.

Caceres, C., Guzzo, V., \& Segoviano Basurto, M. (2010). Sovereign spreads: Global risk aversion, contagion or fundamentals? IMF working papers, 1-29.

Caporale, G. M., Spagnolo, F., \& Spagnolo, N. (2017). Macro news and bond yield spreads in the euro area. The European Journal of Finance, 1-23.

Clark, E., \& Kassimatis, K. (2015). Macroeconomic effects on emerging-markets sovereign credit spreads. Journal of Financial Stability, 20, 1-13.

Constantini, M., Fragetta, M., Melina, G. (2014). Determinants of sovereign bond yield spreads in the EMU: An optimal currency area perspective. European Economic Review, 337-349.

De Grauwe, P., \& Ji, Y. (2012). Mispricing of sovereign risk and macroeconomic stability in the Eurozone. JCMS: Journal of Common Market Studies, 50(6), 866-880.

Diehl, A. \& Tatim, D. (2004). Pesquisa em ciências sociais aplicadas: métodos e técnicas. São Paulo. Prentice Hall.

Driscoll, J. C., \& Kraay, A. C. (1998). Consistent covariance matrix estimation with spatially dependent panel data. Review of economics and statistics, 80(4), 549560.

Edwards, S. (1986). The pricing of bonds and bank loans in international markets: An empirical analysis of developing countries' foreign borrowing. European Economic Review, 30(3), 565-589. 
Eichengreen, B., \& Mody, A. (1998). What explains changing spreads on emerging-market debt: fundamentals or market sentiment? (No. w6408). National Bureau of Economic Research.

Eurostat (2016) http://ec.europa.eu/eurostat

Faini, R. (2006). Fiscal Policy and Interest Rates in Europe", Economic Policy, vol. 21(47), 443-489.

Fávero, L. P. L (2015). Análise de Dados: Modelos de regressão com Excel囚, Stata $\circledast$ e SPSS $® .1^{\text {a }}$ edição - Rio de Janeiro: Elsevier.

Frank, N., \& Hesse, H. (2009). Financial spillovers to emerging markets during the global financial crisis (No. 9-104). International Monetary Fund. 1.

Gil, A. (2007) Métodos e Técnicas de Pesquisa Social. 5. ed. São Paulo. Atlas.

Hallerberg, M., \& Wolff, G. B. (2008). Fiscal institutions, fiscal policy and sovereign risk premia in EMU. Public Choice, 136(3-4), 379-396.

Hilscher, J., \& Nosbusch, Y. (2010). Determinants of sovereign risk: Macroeconomic fundamentals and the pricing of sovereign debt. Review of Finance, rq005.

Hoechle, D. (2007). Robust standard errors for panel regressions with crosssectional dependence. Stata Journal, 7(3), 281.

Kobbeltvedt, T., Brun, W., \& Laberg, J. C. (2005). Cognitive processes in planning and judgements under sleep deprivation and time pressure. Organizational Behavior and Human Decision Processes, 98(1), 1-14.

Krishnamurthy, A. (2010). How debt markets have malfunctioned in the crisis. The Journal of Economic Perspectives, 24(1), 3-28.

Kriz, K. A., Wang, Q., \& Issarachaiyos, S. (2015). Debt burden and perceived sovereign default risk: evidence from credit default swaps. Public Finance and Management, 15(3), 203. 
Lakatos, E. \& Marconi M. (2011). Metodologia científica. 6. ed. São Paulo. Atlas.

Lamfalussy, A. (1989). Macro-coordination of fiscal policies in an economic and monetary union in Europe. Paper annexed to the Report on Economic and Monetary Union in the European Community (commonly called the Delors Report). Committee for the Study of Economic and Monetary Union, 91-126.

Lane, P. R. (2012). The European sovereign debt crisis. The Journal of Economic Perspectives, 26(3), 49-67.

Lemmen, J. J., \& Goodhart, C. A. (1999). Credit risks and european government bond markets: a panel data econometric analysis. Eastern Economic Journal, 25(1), 77-107.

Maltritz, D. (2012). Determinants of sovereign yield spreads in the Eurozone: A Bayesian approach. Journal of International Money and Finance, 31(3), 657-672.

Mellan, O. (2009). Reassessing risk. Independent Advisor.

Ordoñez-Callamand, D., Gomez-Gonzalez, J. E., \& Melo-Velandia, L. F. (2017). Sovereign default risk in OECD countries: do global factors matter? (No. 996). Banco de la Republica de Colombia.

Pan, J., \& Singleton, K. J. (2008). Default and recovery implicit in the term structure of sovereign CDS spreads. The Journal of Finance, 63(5), 2345-2384.

Powell, A. \& Martinez S, J. F., (2008). On emerging economy sovereign spreads and ratings. IDB Working Paper, No. 530.

Roszkowski, M. J., \& Davey, G. (2010). Risk perception and risk tolerance changes attributable to the 2008 economic crisis: A subtle but critical difference. Journal of Financial Service Professionals, 64(4), 42-53.

Standard \& Poor's. (1998) Sovereign Defaults Continue to Decline in 1998. Credit Week. 
Silvapulle, P., Fenech, J. P., Thomas, A., \& Brooks, R. (2016). Determinants of sovereign bond yield spreads and contagion in the peripheral EU countries. Economic Modelling, 58, 83-92.

Takeshy, T. \& Mendes, G. (2006). Como fazer Monografia na prática. Rio de Janeiro. 


\section{GLOSSÁRIO}

Bail-out

BCE

CDS

Default

Déficit fiscal

Euribor

Flight-to-quality

Maturidade
Resgate. Ajuda financeira oferecida a uma instituição ou país em dificuldade para honrar seus compromissos financeiros.

Banco Central Europeu.

Credit Default Swaps. Instrumento financeiro derivativo em que se negocia a garantia de pagamento de um determinado título em caso de default.

É o descumprimento de cláusula importante de um contrato de crédito. Calote.

Quando o governo gasta mais do que arrecada. $O$ déficit público equivale à parcela de despesas realizadas que não estão cobertas pela receita fiscal.

Taxa de juros média cobrada pelos bancos europeus entre si. Taxa interbancária dos países da zona Euro.

Refere-se a uma mudança no tipo de investimentos almejados pelos investidores em períodos de crise. Nesses períodos, os investidores preferem ativos considerados mais seguros e com menor risco, ou seja, eles movem seu capital de ativos de maior risco para ativos de menor risco.

É uma medida de prazo. Refere-se a uma data específica em que $\mathrm{o}$ instrumento financeiro expira e se dá a liquidação da obrigação. 
PEC

PIB

PIIGS

Prêmio de risco

Risk free rate

Spread
O Pacto de Estabilidade e Crescimento (PEC)

é um acordo firmado pelos membros da comunidade europeia que reúne um conjunto de regras e instrumentos com o objetivo de coordenar as políticas orçamentais nacionais e, por essa via, garantir o saneamento das finanças públicas dos países-membros.

PIB é a sigla para Produto Interno Bruto, e representa a soma, em valores monetários, de todos os bens e serviços finais produzidos numa determinada região, durante um período.

Acrônimo pejorativo utilizado para identificar o grupo dos países: Portugal, Itália, Irlanda, Grécia e Espanha.

É a diferença matemática entre o rendimento de um título público de um país em relação ao rendimento de um título público de outro país, de mesma maturidade, considerado seguro. É o retorno adicional que os investidores desejam obter para aceitar correr maior risco. Quanto maior for a probabilidade de calote desse papel, maior será o prêmio.

Taxa livre de risco. Essa taxa é utilizada como referência para análise de risco relativo, ou seja, é a taxa que utilizamos para calcular o prêmio de risco do ativo financeiro.

É o prêmio de risco que os emissores de títulos de crédito de baixa qualidade devem pagar para atrair investidores. 
Subprime

Superávit primário

S\&P 500

Treasury rate

VIX

Yield
O termo é empregado para designar uma forma de crédito hipotecário que não oferece garantias suficientes, ou seja, um investimento com maior risco.

É a diferença entre receitas e despesas do governo, excluindo-se da conta as receitas e despesas com juros. Caso essa diferença seja positiva, tem-se um "superávit primário". O superávit primário indica quanto o governo economizou ao longo de um período com vistas ao pagamento de juros sobre a sua dívida.

O índice S\&P 500 é composto por quinhentas ações selecionadas das duas principais bolsas americanas, NYSE e NASDAQ. As ações são escolhidas em virtude do seu tamanho de mercado, liquidez e representação de grupo industrial. Na composição do índice, cada ação é ponderada por seu valor de mercado.

É a taxa de juros que o governo americano paga para tomar dinheiro num determinado prazo.

É a sigla para Chicago Board Options Exchange Volatility Index. Esse índice é construído usando a volatilidade implícita das opções sobre ações do S\&P 500. É uma medida usada no mercado financeiro para auferir aversão a risco do investidor num geral.

Yield é um termo inglês que significa rendimento, lucro. Yield para títulos é o 
74

cupom anual dividido pelo preço de compra atualizado do papel. 


\section{APÊNDICE}

Saídas do Software Stata

\section{Modelo linear:}

- xtreg spread gdpreal debt reer, fe

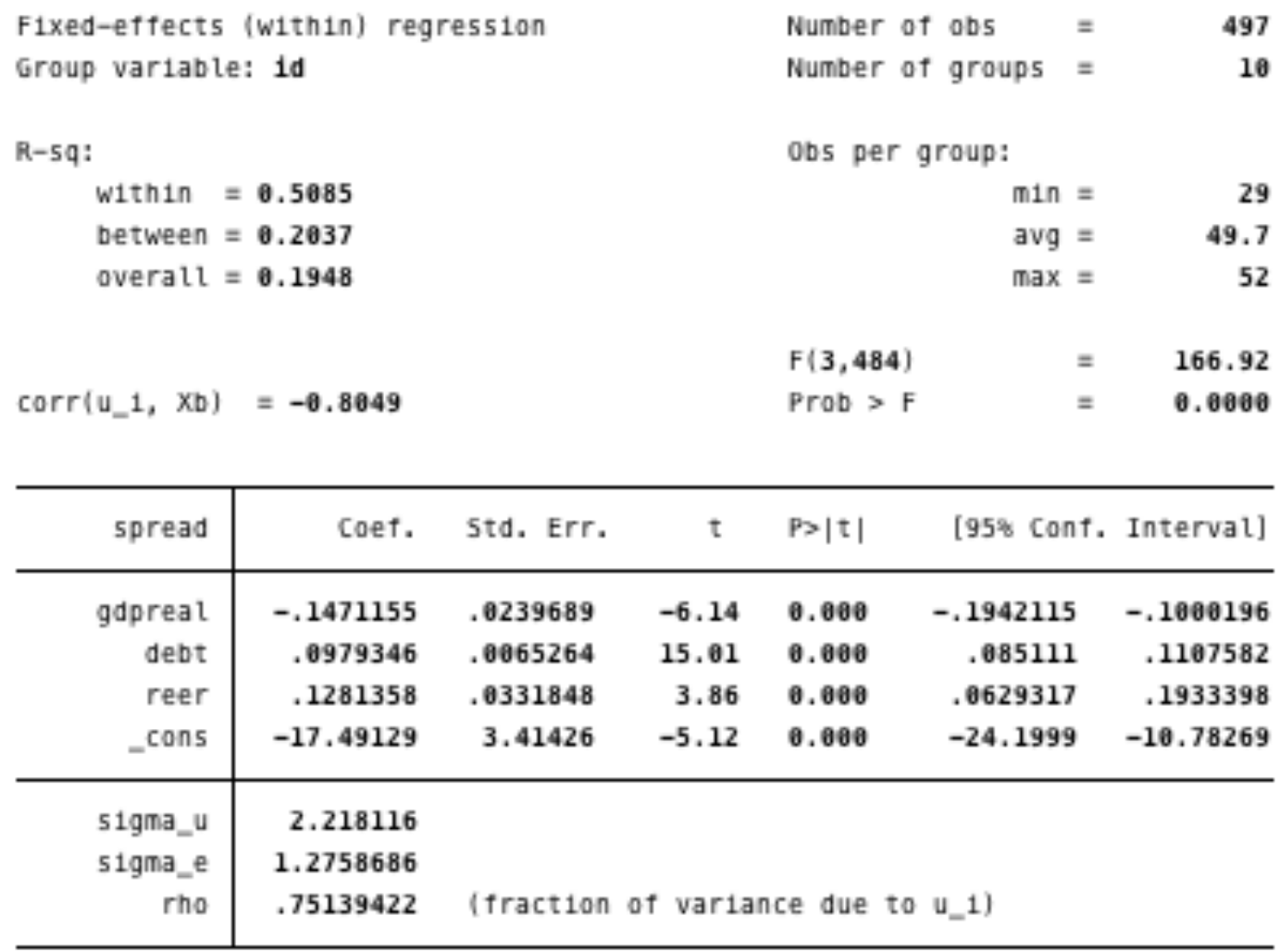

F test that all $u_{-} 1=0: F(9,484)=37.05$ 
Modelo Structural break (1):

- xtreg spread gdpreal debt reer debtd2010 d2010gdpreal d2010reer, fe

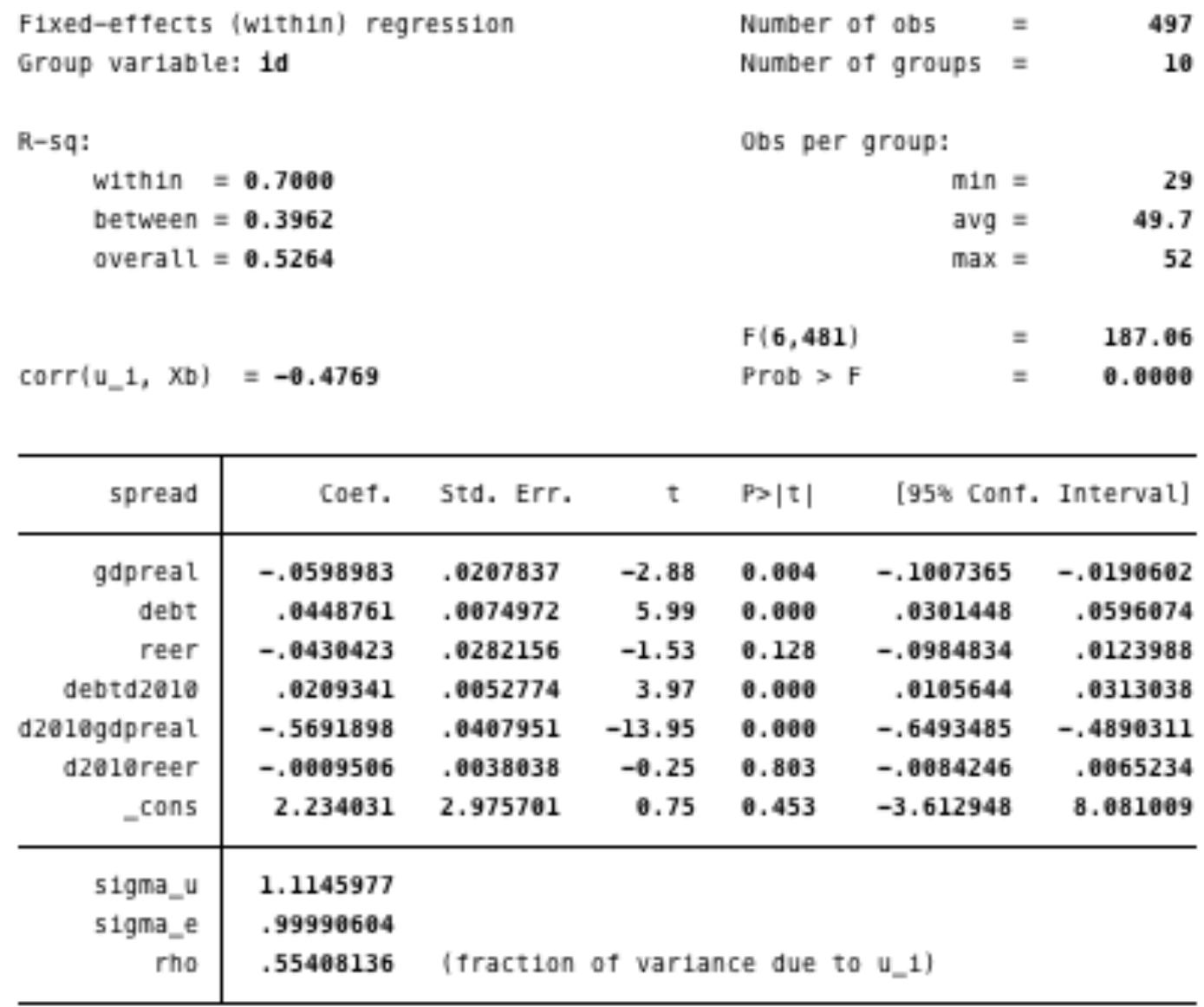

F test that all $u_{-} 1=0: F(9,481)=16.37$

Prob $>F=0.0000$ 
Modelo Structural break (2):

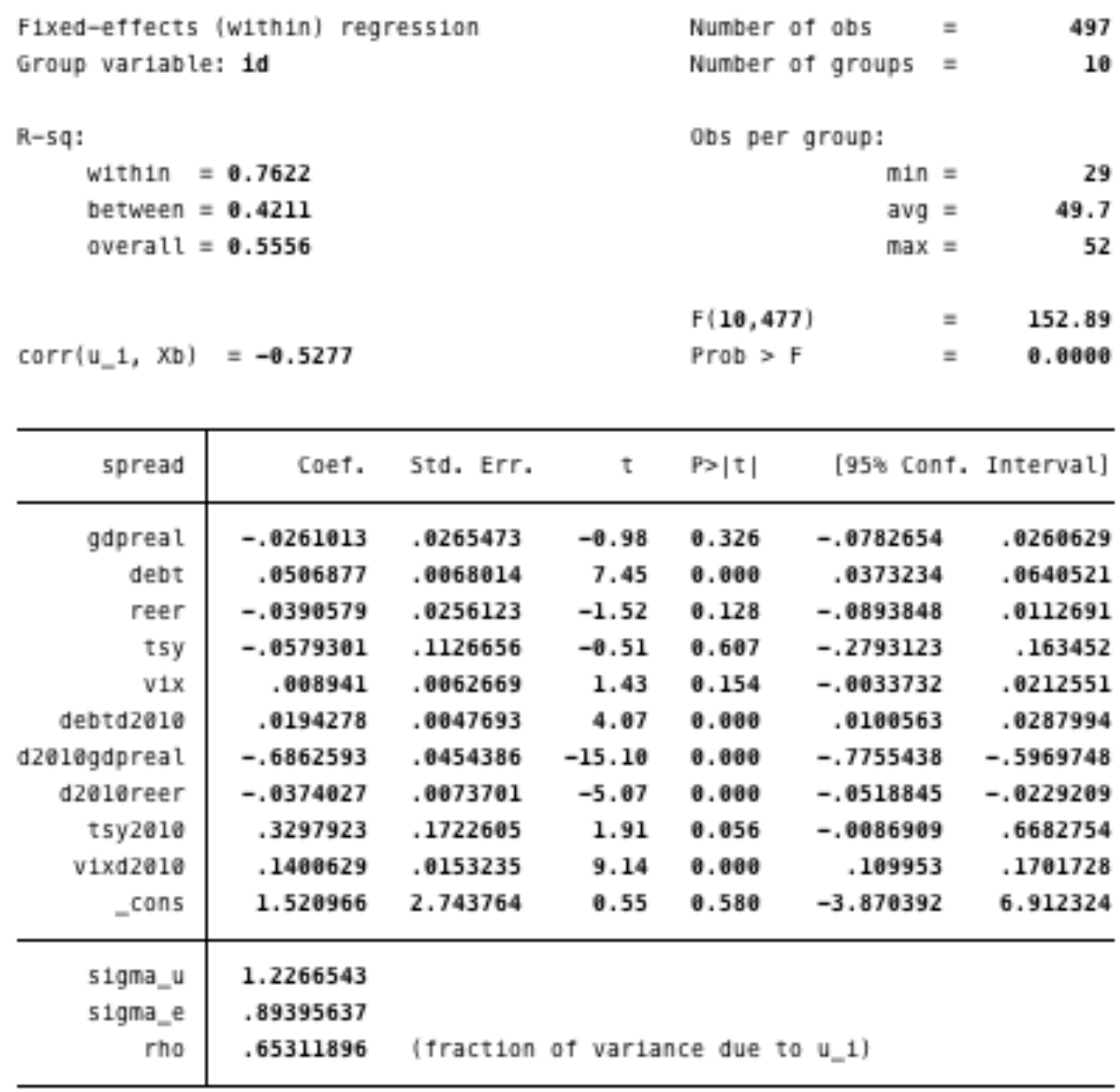

F test that all $u_{-} 1=0: F(9,477)=18.03$

Prob $>F=0.0000$ 
Modelo Structural break (3):

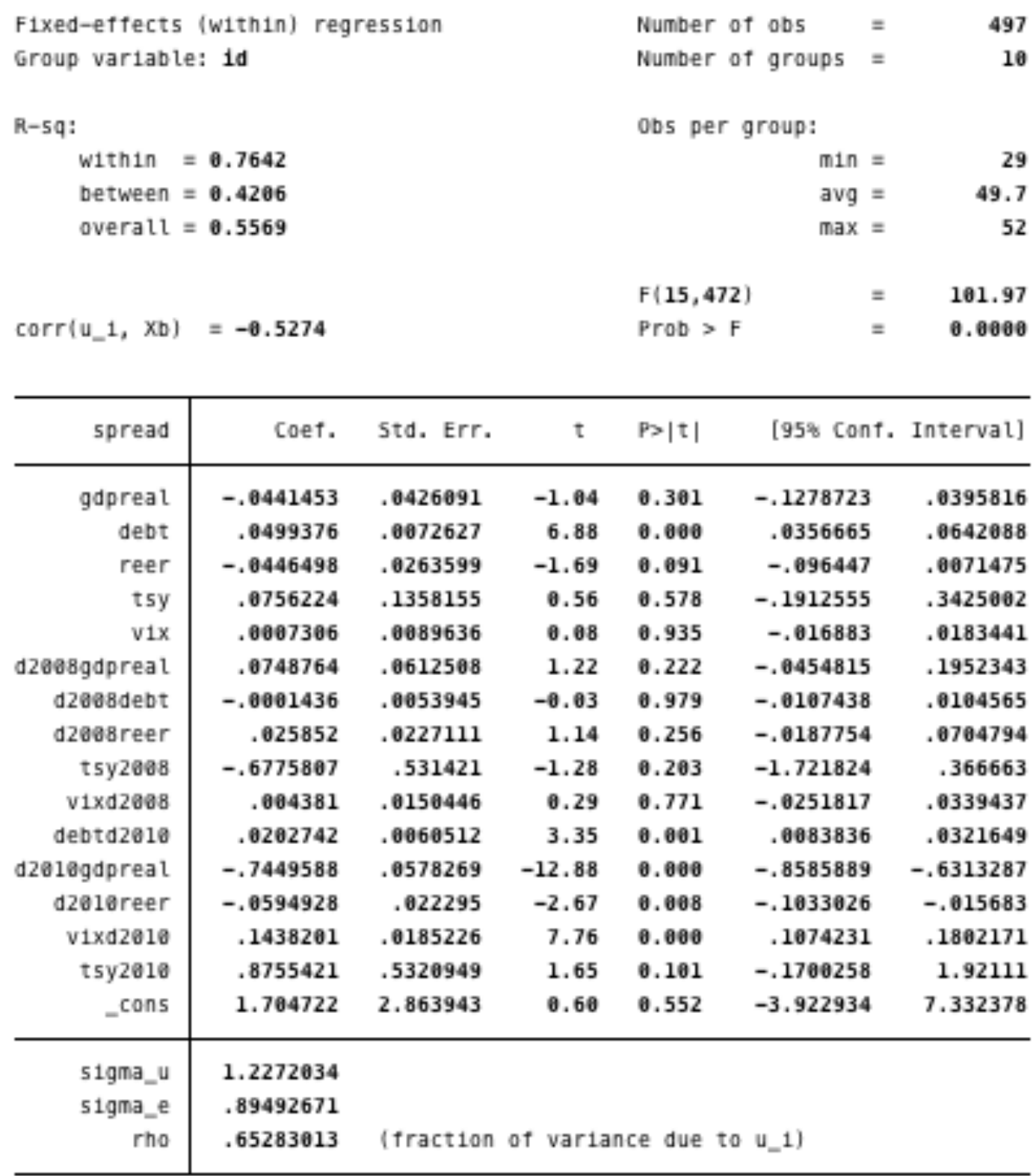


Teste de Hausman:

\begin{tabular}{|c|c|c|c|c|}
\hline & \multicolumn{2}{|c|}{- Coefficients -} & \multirow{3}{*}{$\begin{array}{c}(\mathrm{b}-\mathrm{B}) \\
\text { Difference }\end{array}$} & \multirow{3}{*}{$\begin{array}{c}\left.\text { sqrt (d1ag }\left(V_{-} b-V_{-} B\right)\right) \\
\text { S.E. }\end{array}$} \\
\hline & (b) & (B) & & \\
\hline & $\mathrm{FE}$ & RE & & \\
\hline gdpreal & -.1471155 & -.1771453 & .0300297 & .0050945 \\
\hline debt & .0979346 & .0806793 & .0172553 & .0029364 \\
\hline reer & .1281358 & .1000313 & .0281045 & .0062558 \\
\hline
\end{tabular}

$\mathrm{b}=$ cons1stent under $\mathrm{Ho}$ and Ha; obtained from xtreg $B=1$ inconsistent under $\mathrm{Ha}$, efflclent under Ho; obtained from xtreg

Test: Ho: difference in coefficients not systematic

$\begin{aligned} \operatorname{ch} 12(3) & = & (b-B) \cdot\left[\left(V_{-} b-V_{-} B\right)^{\wedge}(-1)\right](b-B) \\ & = & 35.13 \\ \text { Probsch12 } & = & 0.0000\end{aligned}$

Teste de Hausman Robusto:

test gdpreal_fe debt_fe reer_fe debtd2010_fe d2010gdpreal_fe dze10reer_fe vix_fe tsy_fe v1xd2010_fe tsyze10_fe

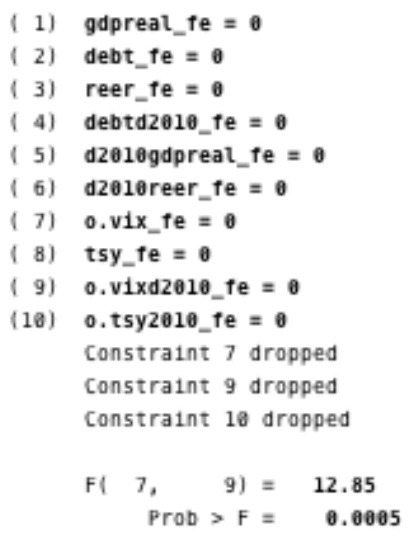

